INTER NATIONAL MONETARY FUND
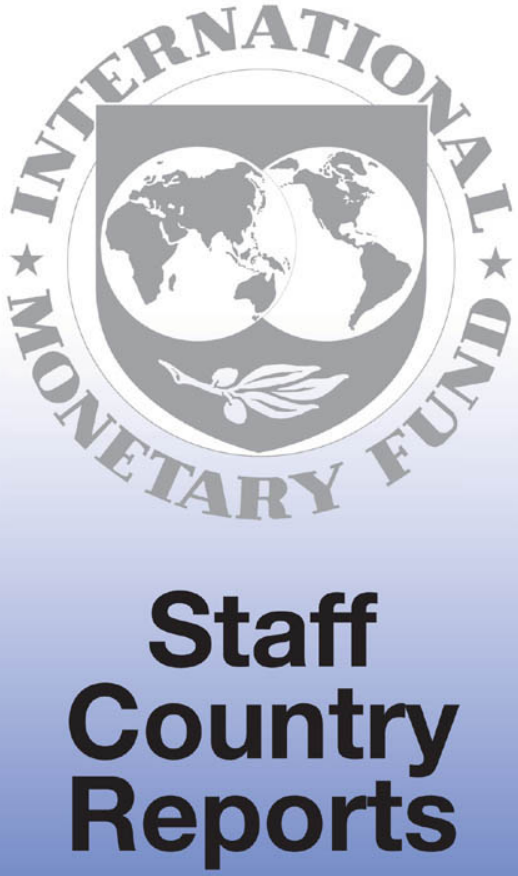


\section{United Kingdom: Staff Report for the 1999 Article IV Consultation}

This report was prepared by a staff team of the International Monetary Fund following discussions with the officials of United Kingdom on economic developments and policies. The report was then considered by the IMF's Executive Board in the context of the IMF"s periodic consultation with United Kingdom, as required under Article $\mathrm{V}$ of the IMF Articles of Agreement. The views expressed in the staff report itself are those of the staff team and do not necessarily reflect the views of the Executive Board of the IMF or of the authorities of United Kingdom; a supplementary statement by IMF staff may also be included. The views of the Executive Board as expressed in the discussion of the Article IV consultation report and as summarized in a Public Information Notice (PIN) are also included. In addition, a statement by the member country authorities may be appended. Further background documentation prepared by IMF staff for the consultation may be published separately at a later date. The policy of publication of Article IV staff reports allows for the deletion of market sensitive information.

This Article IV staff report is published--both in hard copy and on the IMF's website (http://www.imf.org) —as part of a pilot project. To assist the IMF in evaluating the pilot project for release of Article IV staff reports, reader comments on the staff report are invited prior to October 5, 2000, and may be sent by e-mail to Pilotproject@imf.org.

Copies of this report are available to the public from

International Monetary Fund - Publication Services 700 19th Street, N.W. - Washington, D.C. 20431

Telephone: (202) 623-7430 - Telefax: (202) 623-7201

Telex (RCA): 248331 IMF UR

E-mail: publications@imf.org

Internet: http://www.imf.org

Price: $\$ 15.00$ a copy

International Monetary Fund

Washington, D.C. 
INTERNATIONAL MONETARY FUND

\section{UNITED KINGDOM}

\section{Staff Report for the 1999 Article IV Consultation}

Prepared by the Staff Representatives for the 1999 Consultation with the United Kingdom

Approved by Michael Deppler and Leslie Lipschitz

February 9,2000

Contents

Page

Executive Summary 3

I. Introduction

II. Economic Background and Near-Term Macro Policies

A. Recent Developments

B. Near-Term Macroeconomic Prospects and Policy Issues

III. Policy Framework Issues. 12

A. Policy Framework and Outcomes ........................................... 12

B. The Monetary Policy Framework ................................................... 13

C. The Fiscal Policy Framework ..................................................... 18

IV. Longer-Term Structural Issues and Policies....................................... 20

A. Policies for an Efficient and Fair Labor Market........................... 20

B. Pension Reform .................................................................. 22

C. Closing the Productivity Gap: Investment, Competition, and Regulation 22

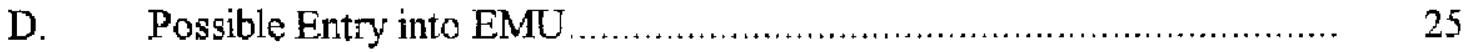

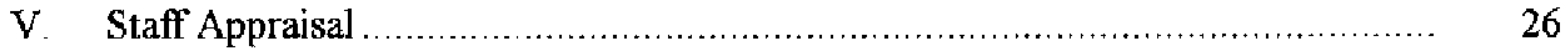

Tables

1. Selected Economic Indicators and Staff Projectors .................................. 38

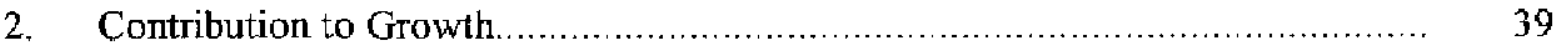

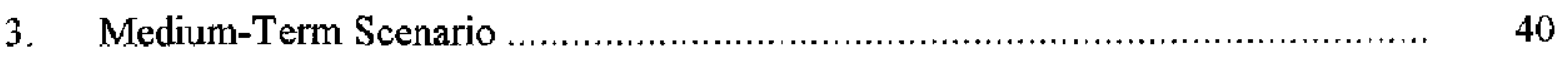


4. Medium-Term Fiscal Balances

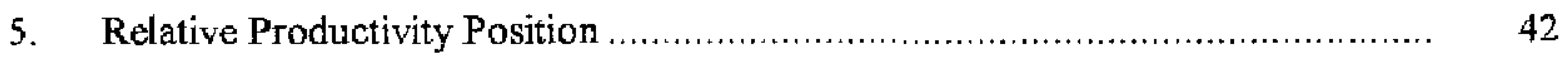

\section{Text Boxes}

1. The Monetary Policy Framework ................................................... 30

2. The Constant Interest Rate Assumption and Alternatives ............................ 31

3. The Fiscal Framework ...................................................................

\begin{tabular}{lll}
\hline $4 . \quad$ Recent Welfare and Labor Market Reforms ............................................... & 34 \\
\hline
\end{tabular}

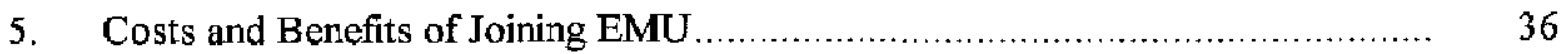

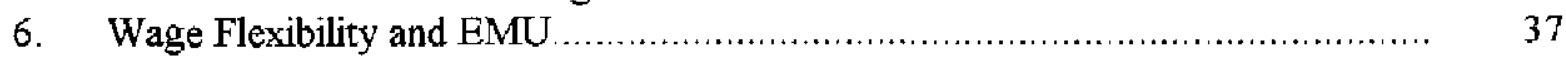

\section{Figures}

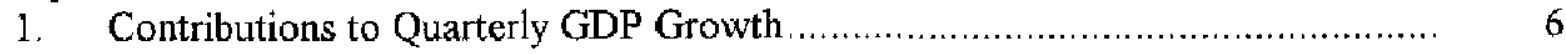

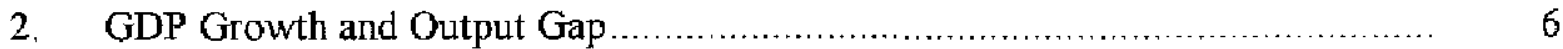

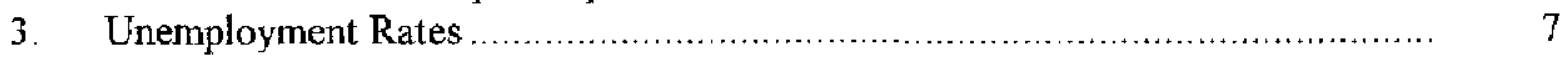

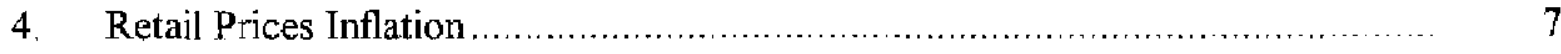

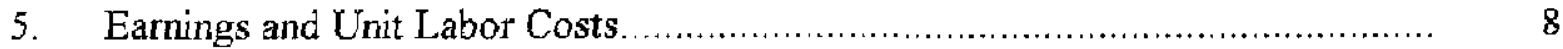

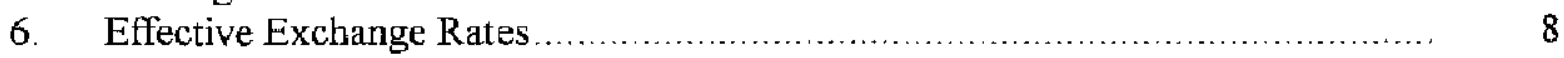

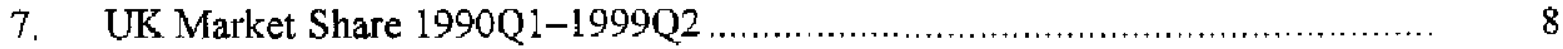

8 Inflation Expectations 10 Years Ahead ........................................... 12

9. Comparative Real Performance in the Medium Term, 1993-99 .................... 14

\begin{tabular}{lll}
10 & MPC's November Inflation Projection on Constant Nominal Interest Rates at 5.5\% $\quad 13$ \\
\hline
\end{tabular}

11. Official and Market Interest Rates: 1/96-12/99 ................................... 15

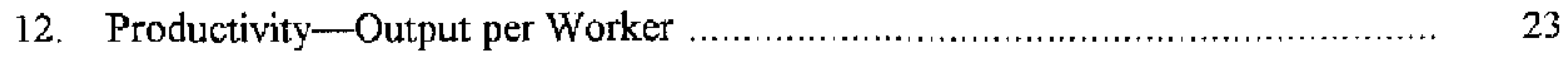

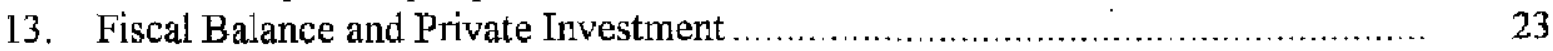

Annex

I. The Reform of the U.K. Pension System ............................................. 43

Appendices

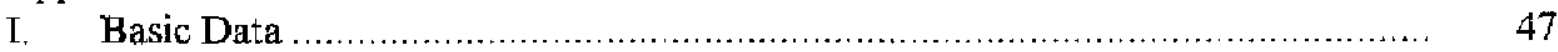

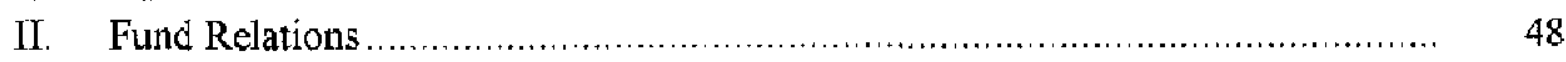

III. Statistical Information ................................................................. $\quad 50$

Appendix Table

6. Core Statistical Indicators ............................................................. 49 


\section{EXECUTIVE SumMaRY}

Background: The economy has bounced back from the effects of last year's global slowdown which led to a temporary and not unwelcome pause in the U.K.'s output growth in late 1998 and early 1999. The economy is now roughly at its non-inflationary potential, and unemployment is at a 20-year low. Inflation pressures remain largely latent, however, mainly because of temporary price level effects reflecting the lagged impact of sterling appreciation and declines in price-cost margins due to increased competition and deregulation. The external position remains relatively benign, despite the historically high real level of sterling. Although the current account shifted to a deficit of $1 \frac{1 / 4}{4}$ percent in 1999 , concerns over the apparent overvaluation of sterling have diminished in the last year.

Near-term policy issues: The risks to the output and inflation forecast are mainly on the upside and the possibility of overheating beyond the near term remains a concern. The Monetary Policy Committee (MPC) reversed policy direction in September 1999, and by January 2000 had increased the policy rate by a total of 75 basis points to 5.75 percent. Staff and markets expect further increases to be necessary, and forthcoming, in time. The fiscal outlook is turning out stronger than expected owing to stronger output growth and some structural fiscal improvements. Given the inflation risks and the appreciated real exchange rate, and in the interests of consolidating the credibility of the newly-established fiscal framework, staff stressed that the fiscal stance should not be relaxed in the next budget. The authorities were noncommittal.

Policy framework issues: The U.K.'s remarkable economic performance of recent years is due to many factors, but strong policy frameworks have contributed by helping to foster sound macroeconomic and structural policies and-through their emphasis on transparency and accountability-by giving a high degree of credibility to policies and boosting private sector confidence. The monetary policy framework in particular has delivered on its commitment to transparency and forward-looking action. In the staff's view, there is merit, however, to embedding that forward-looking dimension more deeply into the MPC's forecasting process by building in a view about how policy might react to developments along the lines envisaged in the forecast. Such an extension would provide a systematic framework within which the MPC could think through policy options more dynamically, and could also contribute to reducing uncertainty and improving economic performance yet further. The reactions of the Members of the MPC were mixed, although they were unanimous in doubting that the Committee could agree on a policy reaction function given their divergent individual views. Many Members also questioned whether the Committee should "reveal its hand." While these are substantive concerns, the staff felt that they should not deter the MPC from pressing ahead with improving its forecasting framework. The medium-term orientation of the fiscal framework has provided a measure of assurance to the public that the public finances will be managed prudently on a sustained basis. While fiscal transparency is high by international standards, in the staff's view, it could be strengthened further by improvements in the area of budget reporting. 
Longer-term structural issues and policies: With macroeconomic policies and frameworks set to deliver sustained growth and low inflation, the focus of longer-term policies has shifted towards achieving greater equity and strengthening productivity. The Government's recent welfare and labor market reforms are appropriately geared to strengthening incentives to work. To close the productivity gap vis-à-vis other major industrialized countries, the United Kingdom needs to increase private and public investment rates on a sustained basis. Given the already high level of the real exchange rate and the risks of relying excessively on foreign savings, boosting domestic savings seems to be a prudent option, and the most effective means to achieve this would be to increase public saving. In this regard, staff felt there may be a case for strengthening the fiscal rules beyond the golden rule to require higher public savings and fiscal balance over the cycle.

Entry into EMU remains a key medium-term decision for the United Kingdom. Although many factors will influence the decision whether to join, an overriding economic case for or against entry cannot be made at this moment. However, many of the uncertainties are likely to lessen over time. 


\section{INTRODUCTION}

1. Discussions for the 1999 Article IV consultation with the United Kingdom were held in London during November 12-22. ${ }^{1}$ The staff representatives met with Chancellor Brown, Governor George, other senior officials of the Government and the Bank of England, and representatives of financial institutions, independent research institutes, business, and trade unions. Messrs. Pickford (Executive Director) and Burgess (Assistant to the Executive Director) attended the meetings. The United Kingdom has accepted the obligations of Article VIII, sections 2, 3, and 4.

2. At the conclusion of the previous consultation on March 3, 1999 (SUR/99/28), Directors commended the United Kingdom's impressive economic performance of recent years and welcomed the strengthening of the macroeconomic policy framework through a clear medium-term orientation, guided by the principles of transparency, accountability, and credibility. They noted the authorities had established a sound fiscal position and underscored the need to adhere to budget plans for sustaining approximate structural balance. Directors considered monetary policy to be the instrument of choice to promote short-run macroeconomic stability and saw scope for a further easing to avoid an excessive weakening of activity. While agreeing that the decision on the euro was in large part political, they noted that if a decision were made to join the EMU, the transition would be facilitated by continuing reforms to enhance the economy's flexibility, especially as regards real wages.

3. The mission found that macroeconomic prospects for the United Kingdom remain good. A key policy challenge over the medium term will be to prevent the emergence of overheating, but the monetary framework in particular provides reasonable assurance that the necessary policy action will be taken. In view of the basically sound macroeconomic policies and strong performance, much of the discussions centered on the policy frameworks and longer-term structural reforms that have been key to establishing the credibility of policies and ensuring good outcomes. Building on policy framework issues covered in last year's consultation, this staff report focuses on how these frameworks and reforms could be strengthened further to meet the main tasks facing policy makers - that of sustaining stable economic growth and raising productivity while ensuring that these gains are shared equitably.

\footnotetext{
${ }^{1}$ The staff team comprised Mr. Deppler (Head), Ms. Coorey, and Messrs. Escolano, Aitken, Swagel (all EUl) and Laxton (RES).
} 


\section{ECONOMIC BACKGROUND AND NEAR-TERM MACRO POLICIES}

\section{A. Recent Developments}

4. The economy has bounced back from the effects of last year's global slowdown which led to a temporary and not unwelcome pause in the U.K.'s output growth in late 1998 and early 1999. Exports and related movements in inventories accounted for most of the gyrations in growth. Final domestic demand, and especially consumer spending, remained strong throughout - bolstered by a proactive 250 basis point cut in the policy rate between October 1998 and June 1999 - and was mainly responsible for keeping the slowdown even shallower than originally expected (Figure 1). The pick up in output growth since then (averaging 3 percent at an anmual rate in the last three quarters of 1999) has also been stronger than anticipated reflecting both buoyant consumption spending and, more recently, a pick up in exports. Growth has been strongest in the service sector, but manufacturing output has also risen markedly in recent months.

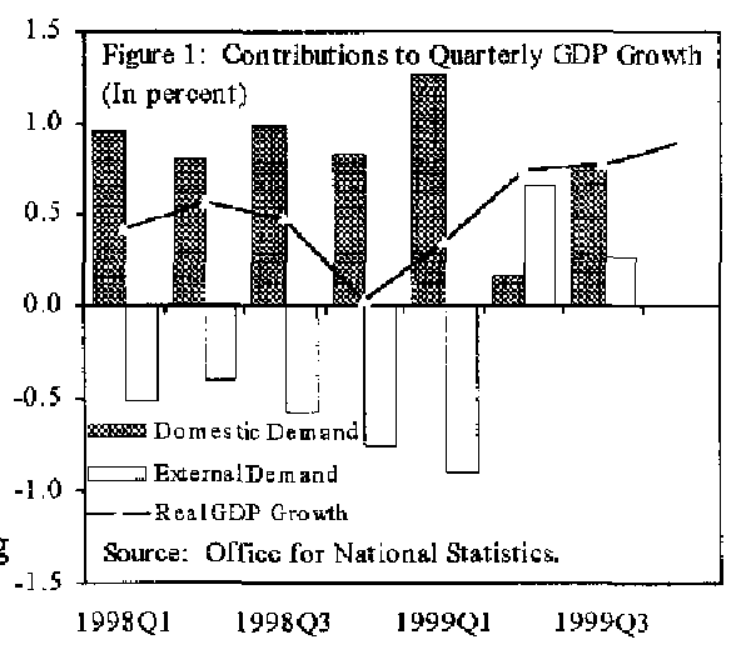

5. The slowdown barely made a dent in resource utilization, and the economy is now roughly at its non-inflationary potential (Figure 2). Unemployment, which peaked at about $10 \frac{1}{2}$ percent in the early 1990 s (on a claimant count basis), continued to edge down to a 20 -year low of 4 percent (5.9 percent on an ILO definition ) (Figure 3 ). Indicators such as vacancies and skill shortages also suggest a tightening labor market.

\section{Inflation pressures remain largely latent,} however. Mainly because of temporary price level effects reflecting the lagged impact of sterling appreciation and declines in price-cost margins due to increased competition and deregulation, falling goods

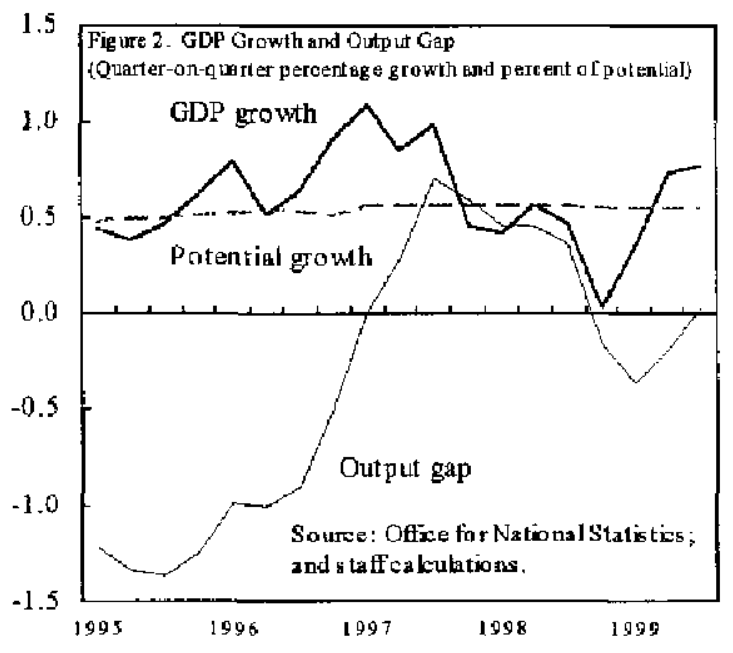


price inflation has more than offset accelerating service price increases, and the overall index of retail price inflation (RPIX) has been undershooting the $2 \frac{1}{2}$ percent target (Figure 4). ${ }^{2}$ Inflation remained steady at 2.2 percent in December (1.2 percent on a HICP basis). The 12-month increase in house prices -usually a leading indicator of overall price pressures---picked up to around 1316 percent in December-January, and mortgage equity withdrawal also picked up. The picture in the labor market is also mixed: average earnings growth has edged up to a range of $4 \frac{1}{2}-5$ percent in recent months and real wages have outstripped productivity growth, which has been slowing since 1994 (Figure 5); but pay settlements have

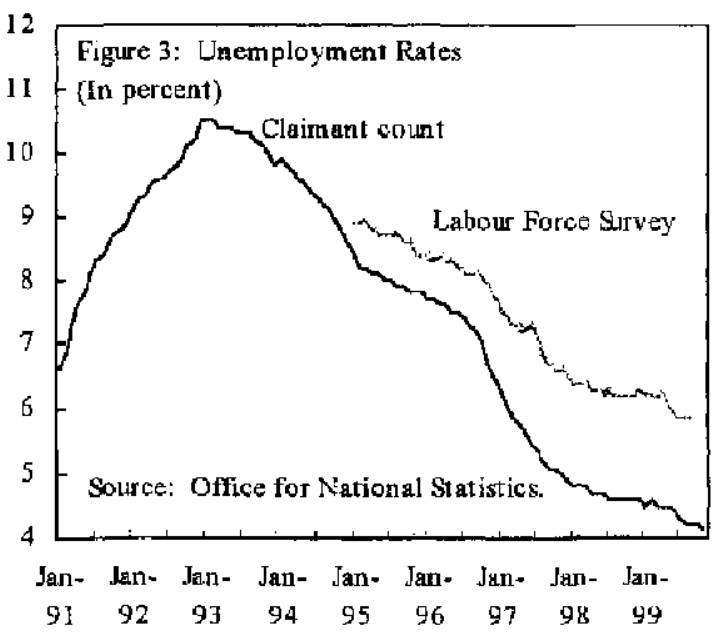

trended down to about $31 / 2$ percent, possibly reflecting declining inflation expectations or a downward shift in the NAIRU - which had been estimated at 7 percent last year. ${ }^{3}$ The large number of pay settlements due in early 2000 may provide a clearer indication of the strength of underlying inflationary pressures.

7. The external position remains relatively benign, despite the historically very high real level of sterling. The real exchange rate appreciated sharply in 1997 reflecting both nominal appreciation and increased unit labor costs, and has remained strong since (Figure 6). The current account shifted to a deficit of $1 \frac{1}{4}$ percent in 1999 with net exports contributing negatively to growth.

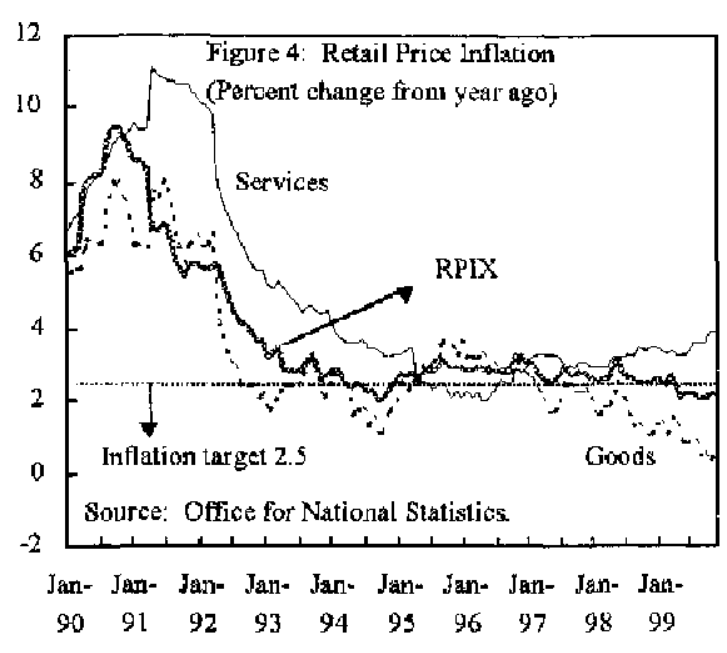

${ }^{2}$ RPIX inflation excludes the effect of mortgage interest payments on prices and is the measure of inflation targeted by monetary policy. It differs from the EU-wide measure, the Harmonized Index of Consumer Prices (HICP), mainly due to the different treatment of housing costs and a different weighting system.

${ }^{3}$ Survey data suggest that 12 -month inflation expectations have declined from $3-3 \frac{1}{2}$ percent in 1998 to below $2 \frac{1}{2}$ percent. Longer-term inflation expectations are harder to gauge. Bond-yield based measures suggest a pick up in inflation expectations in the 2-5 year horizon, with a decline back to about $2 \frac{1}{2}$ percent beyond the 10 year horizon. However, these data are affected by difficulties in estimating the real yield curve due to the relatively small number of index-linked bonds that are issued (there are only four such bonds with a maturity of eight years or less) and the fact that yields are indexed to RPI, rather than RPIX, inflation and hence includes the effects of interest rate changes on prices. 
However, concerns over the apparent overvaluation of sterling have diminished significantly in the last year. Exporters appear to be adjusting to the high level of sterling and there is little evidence of a significant decline in market share in recent years (Figure 7). Indeed the export slowdown in late 1998 was driven mainly by the deceleration in demand in Europe and Asia, rather than a decline in competitiveness. Similarly, while the recent rebound in export growth is associated with the recovery of demand in these markets, it also does not suggest pressing competitiveness concerns. Staff's analysis of real exchange rates based on a macroeconomic balance approach suggests a modest (single digit) overall overvaluation of sterling, with a larger overvaluation against the euro partly offset by undervaluation against the U.S. dollar. ${ }^{4}$

\section{B. Near-term Macroeconomic Prospects and Policy Issues}

8. The key risk is overheating. The economy is more or less at potential; domestic demand has been, and is expected to continue to be, buoyant; external demand is slated to pick up; and the present level of the exchange rate is not expected to be much of a problem. The basic prospect, therefore, is for gathering momentum and eventual overheating--were it not for the generalized expectation that the Bank of England will raise interest rates by the amount necessary to achieve the $2 \frac{1}{2}$ percent inflation target.

9. The staff and the authorities were in broad agreement on the economic outlook, although with some nuances that are somewhat masked by differences in the assumed path of interest rates. The Bank of England 's forecast, in particular, is based on a constant interest rate assumption (discussed further in Section III.B), while the staff forecast assumes that

\footnotetext{
${ }^{4}$ The methodology underlying the macroeconomic balance approach is discussed in $\mathrm{P}$. Isard and H. Faruqee, Exchange Rate Assessment: Extensions of the Macroeconomic Balance Approach Occasional Paper 167, International Monetary Fund, 1998.
} 
interest rates will rise in line with the market yield curve-which shows short-term rates spiking some 110 basis points above current rates over the next two and a half years. In the staff's forecast, GDP growth is projected to pick up to 3 percent in 2000 from 1.9 percent in 1999 (Tables 2 and 3). Activity is expected to be led by continued growth in domestic demand and a further recovery in exports. The curfent account deficit is projected to average about $1 \frac{1}{4}$ percent of GDP in 1999-2000 (at a constant real exchange rate) while inflation is expected to fall to just below 2 percent during 2000, reflecting the temporary downward price level effects noted above, before rising back toward the target thereafter. The Treasury's forecast is similar, as is the Bank of England's, except that in the latter case inflationary pressures are expected to be a bit more delayed and net exports are not quite as buoyant.

10. The risks to the output and inflation forecast are mainly on the upside and the possibility of overheating beyond the near term remains a concern. Staff projects GDP growth to slow down to slightly below the potential growth rate of $2 \frac{1}{2}$ percent over the medium term, so that the output gap is gradually closed (see Table 3 ). This reflects mainly the presumed tightening of monetary policy and, to a lesser extent, the drag on net exports from the modest sterling overvaluation. In view of the uncertainties regarding the extent of the output gap, the level of the NAIRU, and the duration of temporary price level effects, the inflation outlook beyond the near term is especially tentative. As discussed further below, the Bank of England"s inflation forecast has the same "saucer-shaped" profile, except that it sees inflation rising steeply through the target by end-2001 - in large part because of its assumption of unchanged interest rates. Downside nisks mainly take the form of a sharp fall in U.S. (and global) equity prices. This would surely have disruptive effects on U.K. demand and output and place sterling under considerable downward pressure. However, the "starting" positions of monetary and fiscal policy and the fact that private sector balance sheets are in a stronger position than in the early 1990 s suggests that the economy's capacity to absorb such a negative shock is considerably stronger than a decade ago.

\section{The Bank of England's Monetary Policy Committee (MPC) reversed policy} direction in September 1999, and by January 2000 had increased the policy rate by a total of 75 basis points to 5.75 percent. Staff and markets expect further increases to be necessary, and forthcoming, in time. The timing and scale of interest rate increases have been controversial within the MPC as it seeks to balance the current lower-than-targeted performance of inflation, on the one hand, and the medium-term risks of higher-than-targeted performance, on the other. The key areas of contention relate to: (i) the robustness of the short-term relationship between output and prices; (ii) possible structural changes in the labor market which have aitered the extent to which pressures on labor supply translate into nominal wage growth; (iii) the magnitude and duration of the impact of changes in price-cost margins due to competitive forces and deregulation; and (iv) the outlook for the exchange rate, which has repeatedly failed to weaken in line with market expectations. These debates and quite subdued actual inflation notwithstanding, the track record of the MPC suggests that it will continue to act in a forward-looking manner. Indeed, the MPC's promptness in taking action and in reversing policy direction, as needed, has sometimes provoked criticism-but as noted 
below (see paragraph 22), there are good reasons why in the U.K. context it may be appropriate not to delay or unduly "smooth" interest rate action.

12. If the key monetary policy issue is when to raise interest rates further, the key fiscal policy issue is whether to "spend" the stronger than budgeted fiscal outturns. The November Pre-Budget Report (PBR) revised the projected fiscal path upward to reflect the stronger-than-expected economic recovery and some structural fiscal improvements, mainly due to measures implemented in past budgets. The projected public sector outturn for 1999/2000 was estimated at a surplus of 0.2 percent compared with the deficit of 0.5 percent envisaged in the original March budget (Table 4). Staff projections point to a somewhat larger over-performance, with the $1999 / 2000$ fiscal surplus estimated at 0.5 percent of GDP or at about 0.3 percent of GDP in cyclically-adjusted terms, which is to be compared with the structural balance (zero) estimated in the budget. ${ }^{5}$ The PBR, which is a consultation document looking toward the March 2000 budget and hence did not include major policy initiatives, ${ }^{6}$ noted the likely over-performance, but did not take a view on whether to use the margins so created.

\section{The mission stressed that the March 2000 budget should not use the margins} built up by the overperformance the previous year and instead aim to keep the structural fiscal balance unchanged. With overheating being the predominant risk, there was no case for an inflexible instrument like fiscal policy adding to demand pressures. In any case, the margins were not as large as often perceived. By the rules of the fiscal framework, the cyclical component of the overperformance ought not to count, and what was left was rather small (about 0.3 percent of GDP). Moreover, this overperformance was due to an as yet unexplained overperformance on some taxes. It was not so long ago that such surprises had been inexplicably unfavorable (see staff report for the 1996 Article IV consultationSM/96/251, October 2, 1996). This was not a time to assume that unexpected revenue gains might prove to be permanent. A further reason for sticking to existing revenue and

\footnotetext{
${ }^{5}$ The fiscal year runs from April through March. The difference between the two projections reflects slightly different assessments of potential output. The staff's estimates also include some ongoing expenditure savings (in the form of lower unemployment assistance, social benefits, and debt service), which the authorities were, for reasons of prudence, reluctant to take for granted but that, in fact, are unlikely to be reversed during the rest of the fiscal year.

${ }^{6}$ The announced policy initiatives included cuts in capital gains taxes to encourage investment in entrepreneurial ventures and employee share ownership participation schemes; earmarking of fuel excises for investment in road infrastructure and public transportation while replacing automatic increases in real rates by discretionary increases; extension of active labor market policies (the New Deal) to unemployed over 25 years of age; and integration and further definition of the working families and children's tax credits into a single income support program.
} 
expenditure plans was to consolidate the credibility of the government's newly-established fiscal framework with its panoply of three-year departmental expenditure limits (DELs) covering the period 1999/2000-2001/2002. These needed to be adhered to if the mediumterm orientation of fiscal policy was to gain in credibility. The authorities agreed that these considerations were pertinent. They observed that one of the stated objectives of fiscal policy-within the context of the medium-term oriented fiscal framework-was to support monetary policy in the short-run. ${ }^{7}$ They also pointed out that their projections erred on the side of caution (e.g., being based on a lower potential growth rate than would be obtained by the usual estimation methods and in not taking into account ongoing expenditure savings). Nonetheless, they preferred to remain noncommittal regarding their intentions at this point given the consultative nature of PBR which had just been issued and since both the fiscal position and new policies would be evaluated afresh at the time of the next budget in March 2000.

\section{Given that the level of the real exchange rate does not appear to be a major} problem at present, there is not much of a case for fiscal tightening based on policy mix considerations. In principle, the strong appreciation of the real exchange rate and the deterioration of the current account could signal a situation where an excessive burden was being placed on monetary policy to stem domestic demand pressures, while fiscal policy was not being tightened sufficiently. However, as discussed above, the level of sterling-although high by recent historical standards - does not appear to be posing a significant problem for competitiveness while the strong recovery of manufacturing output and exports indicates that the deterioration in the current account will be contained. Moreover, after several years of tightening, the fiscal position is now in a relatively strong position with the net public debt ratio standing at less than 40 percent of GDP and projected to decline over the medium term. The authorities noted that the present policy framework - under which fiscal policy was given a medium-term cast while monetary policy was mainly charged with promoting short-run macroeconomic stability - was well suited for achieving policy credibility and economic stability in the U.K context and that they saw little immediate need to tighten the fiscal stance to counter the strong real exchange rate.

\footnotetext{
${ }^{7}$ According to the Novernber 1999 PBR documents (Analysing U.K. Fiscal Policy), in addition to medium-term objectives, the short-term objectives of the Governments' fiscal policy are "supporting monetary policy, where possible, by:
}

- allowing the automatic stabilizers to play their role in smoothing the path of the economy in the face of variations in demand; and

- where prudent and sensible, providing further support to monetary policy through changes in the fiscal stance. For example, it is likely to be more appropriate to change the fiscal stance in this context if the economy is projected to be some way from trend." 


\section{POLICY FRAMEWORK ISSUES}

\section{A. Policy Framework and Outcomes}

\section{While the United Kingdom has a long, if not always happy, history of} elaborating frameworks for policy, the 1990 s stand out as a period when increasingly explicit and successful medium-term policy frameworks were adopted. The clearest example is monetary policy: The inflation targeting framework adopted in late 1992 was decisively reinforced in May 1997 when the Bank of England's MPC was granted operational independence to pursue a symmetric, $2 \frac{1}{2}$ percent inflation target - an action that has firmly anchored long-term inflation expectations around $2 \frac{1}{2}$ percent, as against 7 percent a decade ago (Figure 8) ${ }^{89}$ In the same vein, the medium-term fiscal framework has also been progressively tightened: the rather vague aim of moving "toward fiscal balance" set out early in the decade was supplanted by a framework requiring at

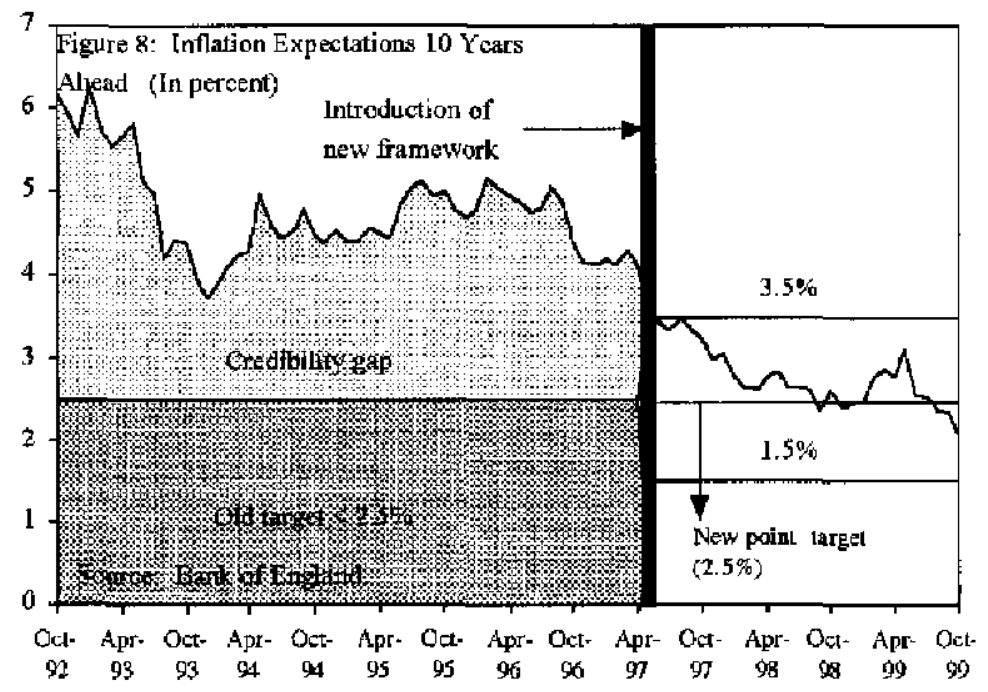
least balance on current account over the cycle--an evolution that saw the PSBR swing from 8 percent of GDP in 1993 to $-1 / 2$ percent in 1999.

16. The policy frameworks have not only delivered what they were set up to do, but also been associated with an improvement in the real performance of the econony that compares with some of the better ones elsewhere. The improvement domestically is well captured by the unemployment rate, which, after trending upwards for three decades, declined monotonically over the 1990 s to levels not seen in almost a quarter century. The U.K. ${ }^{2} s$ real

${ }^{8}$ When inflation targeting was adopted in October 1992, the inflation objective was set at between 1 and 4 percent "with the aim of being in the lower half of that range-that is below $2 \frac{1}{2}$ percent-by the end of the Parliament" (i.e. April 1997). In June 1995, the Government confirmed that a target of $2 \frac{1 / 2}{2}$ percent or less was to apply from the beginning of the following Parliament. (See The New Monetary Policy Framework, HM Treasury, October 1999). Hence, in Figure 8 which shows 10-year ahead inflation expectations, the relevant (medium-term) inflation target before May 1997 is interpreted as $21 / 2$ percent or less.

${ }^{9}$ Other countries achieved similar progress on disinflation. On a comparable (HICP) basis, the United Kingdom's inflation rate had converged to EU levels by 1999 (1.2 versus 1.3 percent, respectively), albeit from a higher starting point in 1991 ( 7.5 versus 5.2 percent). 
performance also holds up internationally. It is comparable to that of the United States and Canada and superior to that of its main European partners over the period since the trough in industrial country activity in 1993. Moreover, that performance stands up despite conditions that are often viewed as adverse - a relatively large fiscal contraction and an (at least partly endogenous) appreciation of the real effective exchange rate (Figure 9).

\section{This performance is due to many factors, but the policy frameworks must have} contributed. Among independent factors, it seems likely that the labor market reforms of the 1980 s were particularly instrumental in permitting a sharp tightening of the labor market in the 1990 s without triggering inflationary increases in pay claims. Nonetheless, the policy frameworks would also seem to deserve part of the credit, not least because they have delivered the promised policies. In this regard, a distinguishing feature of the U.K.'s frameworks is that they insulate the pursuit of broadly sound, stated policies from politics while at the same time making policy makers fully and transparently accountable politically for delivering the rather focused parts for which they have been made responsible. This broad approach is evident in the monetary framework, in the establishment of the Financial Services Authority (FSA) and, to a lesser but increasing extent, in the fiscal framework. The staff has strongly supported these evolutions. By the same token, the staff has focused increasingly on the processes and transparencies associated with these frameworks-the subject of this section.

\section{B. The Monetary Policy Framework}

18. The staff has supported inflation targeting in the United Kingdom since its inception, and has been particularly partial to the framework in place since May 1997 (Box 1). Of the many attributes that contribute to that assessment, two of the more important are the commitments to transparency and to conduct policy in a forward looking manner, a by-product of the mandate to deliver the symmetric inflation target. Basically, the framework has delivered on these two commitments, and on the prospect of good policies which they and other aspects of the framework portend.

19. There is, however, one critical part of the plumbing associated with the framework which is neither transparent nor forwardlooking. This is the constant interest rate assumption used to elaborate the forecast that undergirds the MPC's decision making process and that is featured in the Inflation Report. The intransparency of the assumption is in a sense patent. No one, least of all markets, believes that

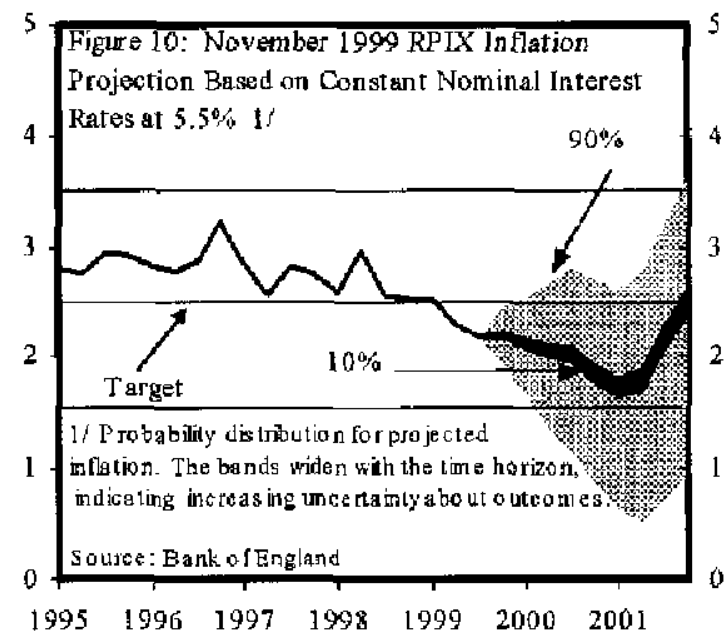
interest rates will remain unchanged absent new information. But the intransparency is also deeper. Because of the assumption, the inflation forecasts published in the Inflation Report 
Figure 9. Comparative Real Performance in the Medium Term, 1993-99

Changes, in percent per annum, except where otherwise noted
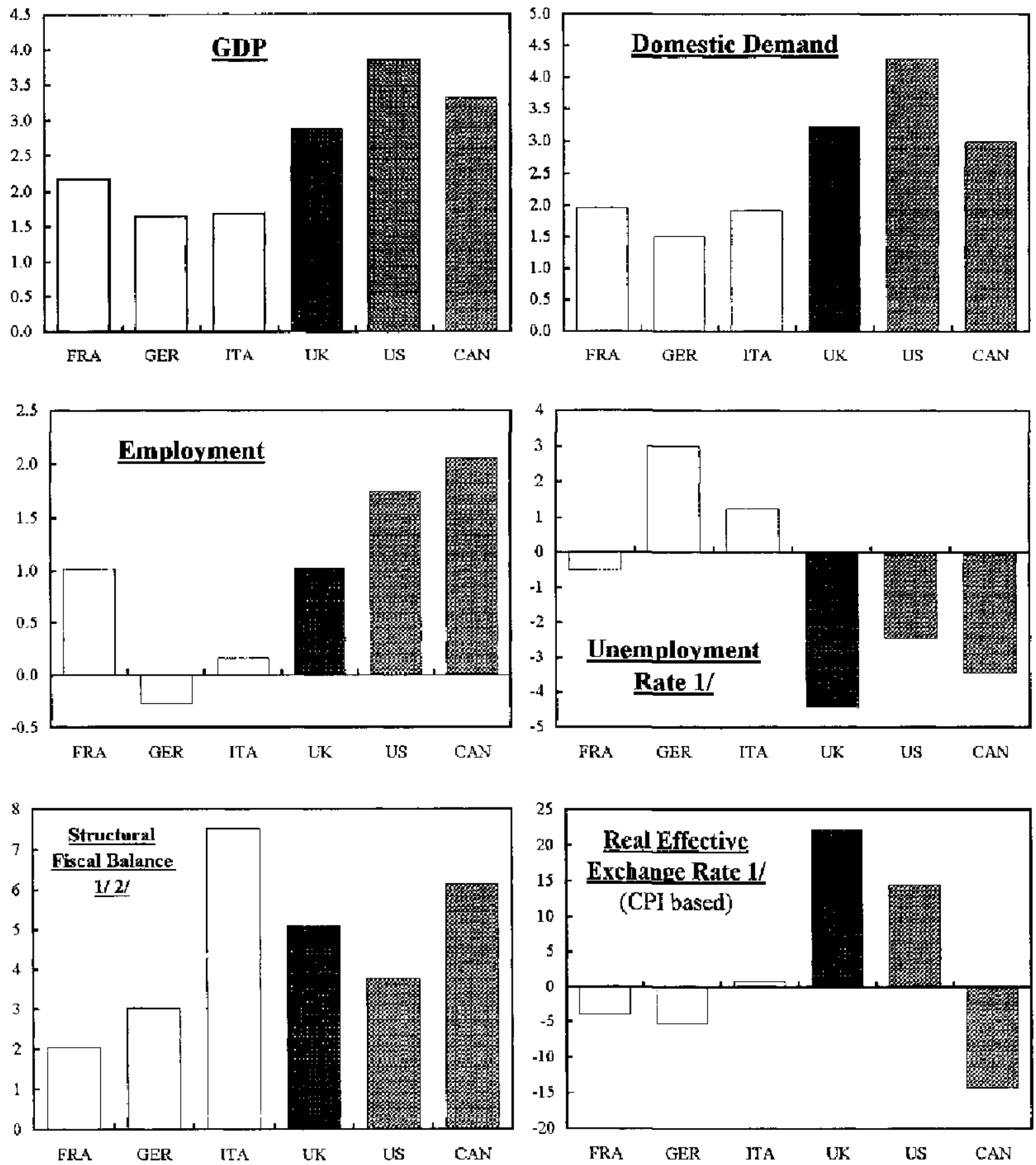

Source: World Economic Outlook; Information Notice System; and OECD, Main Economic Indicators.

1/ Cumulative change

2/ In percent of potential GDP. 
routinely show inflation on target 8 quarters out (by construction, essentially), but generally missing the target at other times (see Figure 10, from the November 1999 Report). Given the interest rate assumption, this is unavoidable; the assumption permits achieving the target at one point, the forecast horizon, but precludes doing so reliably before or after. The implication is, of course, that interest rates will be adjusted next quarter in order to hit the inflation target 8 quarters hence. If one does so, and repeats the process, the end result is a series of smoothed policy reactions that lead to a quite gradual convergence of inflation to targetfeatures that are at odds with the remit, and the perceptions, of the MPC (Box 2). The reason for these untoward implications is the constant interest rate assumption, which is, by its very nature, not forward-looking and therefore out of step with the overall inflation targeting approach in the United Kingdom.

20. Does this matter? In a sense, no. First, if one needs to be nontransparent (an issue we return to below), it is just as well to be patently so. In this respect, the approach taken has been successful: the forecast component of the Inflation Report is widely dismissed by markets as a source of information on likely future actions of the MPC-a view which the mission again heard this year. Second, and more fundamentally, the inflation targeting process as a whole is widely viewed as transparent, owing to the overall framework, and also to the prompt publication of candid, issue-oriented minutes; to the incorporation of similar material more recently into the Inflation Report; and to the open manner in which Members of the MPC report to Parliament and communicate with the public more generally. As a result, markets have anticipated policy rates fairly well, despite the noninformative character of the inflation forecast (Figure 11). Finally, the MPC is widely viewed, including by staff, as having adjusted interest rates in a properly forward-looking and pre-emptive manner.

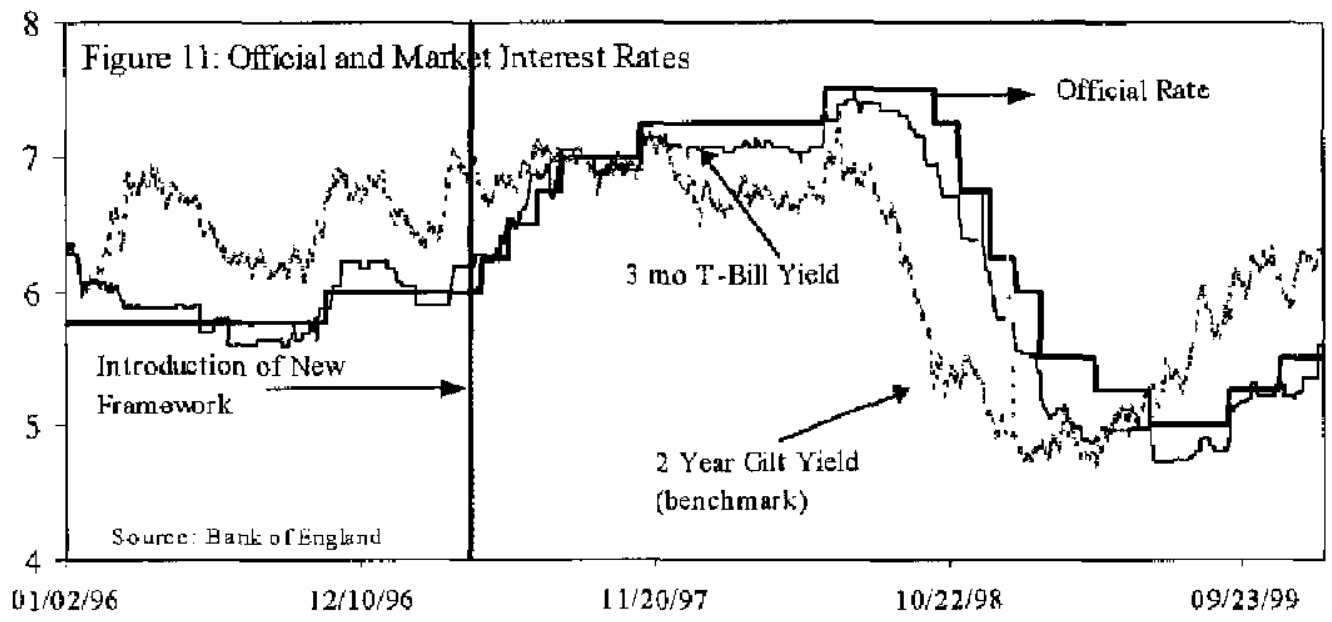

21. But this is not to say that a superficially neutral, but basically misleading, key forecasting assumption does not matter. In this regard, it is important to note that the forecast is the MPC's forecast, not the Bank of England staff's. The Members devote many days each quarter to a step by step elaboration of the forecast. Moreover, they have been unanimous in telling the staff that they viewed the forecast as central to their process-as the element that injected the disciplined forward-looking dimension to their approach and permitted them to get a clear view of where they agreed and disagreed among themselves. In 
many ways, the forecast process is the glue that counteracts the centrifugal forces stemming from the fact that the Members are individually and publicly accountable. Given this context, to observe that somewhere between their activities as forecasters and as decision makers, Members of the MPC somehow overcome the inconsistency deriving from the constant interest rate assumption is not to say that policies would not benefit from changing that assumption.

\section{Staff analysis, based on a parsimonious, but reasonably state-of-the-art policy} simulation cum inflation-targeting model of the U.K. economy, suggests there would be considerable benefits from doing so. ${ }^{10} \mathrm{~A}$ first point coming out of that analysis is that the awkwardness associated with the use of the constant interest rate assumption disappears once interest rates are endogenized via a policy reaction function (see Box 2). The resultant framework fits naturally with both the MPC's remit and how it has been read to operate by markets and staff-one where interest rates are adjusted proactively and inflation tends to converge smoothly and in a reasonably timely manner to the target rate. More fundamentally, endogenizing interest rates naturally leads to a forecasting framework within which to discuss and resolve some of the issues that have been foremost in the Committee's mind of late. A case in point is how to handle the exchange rate, where the Committee has been divided between those favoring an interest parity approach and those wanting to treat it as exogenous. A merit of the staff's analysis is that it brings out both the much larger risks associated with exclusive reliance on the former approach, but also the virtues of a mixed approach. In the same vein, the staff's analysis also speaks to the issue of the proper degree of interest rate smoothing, another issue on which views within the Committee have varied. In this respect, a key point in the staff's analysis is that the appropriate degree of smoothing very much depends on the openness of the economy and its vulnerability to external shocks. That is, a U.S.-style monetary policy is unlikely to be well-suited to the United Kingdom. Finally, and most broadly, endogenizing policy interest rates in the forecast enables policy makers to use the framework in a more forward-looking manner and in a way that helps answer the questions that continually confront policy makers-how fast should one seek to get back on target, how do other objectives of policy (e.g. output and unemployment) affect the pace at which to return to target, and what is the nature of the monetary transmission mechanism. While answers to these questions at any point in time will always be largely judgmental, these judgements will be facilitated by seeking to identify the systematic component.

23. The reactions of the various members of the MPC with whom the staff met were mixed. As noted earlier, there has been considerable ferment in the Committee over a number of issues, some of them related to those raised by staff. However, all of them stressed that the constant interest rate assumption was just that-a convention of the forecasting process rather

${ }^{10}$ See Selected Issues paper on "Issues Relating to Inflation Targeting and the Bank of England's Framework." 
than an optimal or rule-driven path for interest rates. Within this context, the reactions were on two planes. On the technical plane, it was pointed out that the Inflation Report did present alternate forecasts based on market expectations, although it was acknowledged that this did not really meet the staff's point (see Box 2). More generally, there was an interest in and an openness to pushing the frontier of the framework, the immediate frustration being resource constraints. In this vein, some members agreed that it would be useful, at least in principle, to try to inform markets of the MPC's policy reaction function (as distinct from its interest rate forecast, which also depended on subjective assessments of developments and risks over which the MPC had no informational advantage over the market). Developments in this direction were, however, seen to raise a host of difficulties at the practical level. The Members were unanimous in doubting that the Committee could agree on a policy reaction function given their divergent individual views. While this response may have partly reflected the ferment mentioned above, it may be more deeply rooted in the transparent and individual accountability of each Member. More practically still, many Members questioned whether, even supposing that the Committee could come to a reasonably shared view of the future path of interest rates, it should "reveal its hand." The public might misunderstand such information as a commitment on future interest action, and this may create confusion rather than insight; and this in turn might prejudice members' openness to taking a fresh view of the needed policy response every month in the light of new information.

\section{These are substantive concerns, but ones that the staff felt should not deter the} Committee from moving ahead with improving its forecasting framework. As regards the transparency aspects, the Reserve Bank of New Zealand has started to publish a short-term interest rate forecast as part of its Monetary Policy Statement, so far without untoward effects. "However, the institutional set up in New Zealand is rather different: accountability rests with the Governor rather than Committee members individually. It is unclear whether Members could, in a Committee context, agree on a reasonably robust policy reaction function. This is important, for while transparency is a useful discipline, it can be a source of noise and confusion unless there is a reasonable amount of consensus among policy makers to begin with. Given the breadth and depth of its financial markets, the stakes in the case of the United Kingdom are considerably higher than those faced by New Zealand. By the same token, the forecast component of the U.K.'s Inflation Report is a rather awkward tip to the inflation targeting iceberg. Its structure was well-suited to its beginnings in the days before May 1997, when the Governor was essentially warning the Chancellor of the consequences of not taking appropriate interest rate action. It is less suited to a context where the Report is supposed to inform markets of what is likely to lie ahead. In this spirit, the staff urged that the

${ }^{11} \mathrm{~J}$. Flemming "Monetary Policy: Questions of Adequacy, Design and Presentation" Oxford Economic Outlook, October, 1999 also argues that the appropriate procedure would be for the MPC to publish forecasts of short-term interest rates rather than inflation forecasts. He notes the importance of recognizing that such a forecast is not a statement of intent since, in the present framework, the statement of intent relates to the inflation target, not interest rates. 
Committee press ahead with developing the forecasting framework along the lines mentioned. Publication issues could be left for later, once Members acquired a feel for whether, for instance, a "Committee reaction function" might be both useful and workable in the sense that Members felt it embodied a central tendency that nevertheless enabled them to continue to vote as they felt best. While this might not be easy, the staff's analysis does suggest there would be payoffs in terms of improved policy effectiveness. ${ }^{12}$

\section{The Fiscal Policy Framework}

\section{The Government operates under a comprehensive fiscal framework geared} toward sustaining a sound fiscal position and strengthening the composition of public expenditure (Box 3 ). Fiscal soundness is ensured by a debt sustainability rule which is complemented by a golden rule that seeks to protect necessary increases in public investment from pressures for increases in current spending by requiring at least balance on current account over the cycle. The staff has been broadly supportive of this approach, particularly the scope it provides for countercyclical policies, the emphasis it places on protecting infrastnucture investment, and the good outcomes it has delivered so far. The staff has nonetheless also had several interrelated concerns. First, that the golden rule, whether on its own or in tandem with the debt sustainability rule, does not ensure the optimality of public investment. Second, whether the United Kingdom might not be better served by tighter rules, e.g., maintaining overall balance over the cycle. In this regard, it is to be noted that there is little to suggest that economic performance has been adversely affected by the consolidation achieved to date. This is a matter which is discussed further below (see paragraph 36 ) in the context of the authorities' ambition to narrow the productivity gap between the United Kingdom and some of its major trading partners. And, third, because of the authorities' past consolidation efforts, the present rules are well short of binding and would permit a considerably looser policy stance than embodied in present budget plans. ${ }^{13}$ In tandem with the cyclical averaging built in to the strategy, this means that the "constrained discretion" that the exercise is intended to instill is not very constraining and leaves considerable scope for future initiatives. There is a risk, therefore, that this year's spending review will not be used as an opportunity to prioritize spending within a tight overall ceiling that had current spending falling in relation to GDP. This would be unfortunate; at a minimum the continuity intended by the overlap between the last year of the previous DELs and the first year of the new DELs should be preserved.

\footnotetext{
${ }^{12}$ See Section F of the Selected Issues paper on "Issues Relating to Inflation Targeting and the Bank of England's Framework."

${ }^{13}$ The looseness of the fiscal rules relative to budget plans is discussed in greater depth in the staff report for the 1998 Article IV Consultation (SM/99/36, February 10, 1999).
} 


\section{The fiscal framework is also geared towards strengthening the efficiency of} public expenditures, in part through enhanced accountability. In this regard, the authorities stressed that the efficiencies gained from the new framewotk were already becoming evident in the ongoing preparations for the 2000/2001 budget. With spending plans set for three years, departments were not pushing for new allocations to fund new needs (as was the usual pattern), but rather recognized that any such needs would have to be offset with cuts in other spending in order to stay within the DELs. In addition, since unspent appropriations could be rolled over into the next year, departments were not rushing to spend such resources, often inefficiently, at end-year. The authorities also expected additional efficiencies from the introduction of resource accounting in 2000 , especially from the inclusion of capital charges (depreciation) in the current budgets of spending depariments (in contrast to past practice where the only budgeted cost was the initial investment). ${ }^{14}$

\section{While the medium-term orientation of the fiscal framework offers clear} advantages in terms of efficiency gains and improved resource allocation, staff noted that it could also increase resort to indirect means of funding new initiatives. Since the latitude to change the DELs and the possibilities for raising taxes is limited, there could be a temptation to resort to tax expenditures as a means of addressing narrow concerns or funding new initiatives. While welcoming the recent elimination of tax relief for mortgage interest (MIRAS), the mission noted that the March 1999 Budget and the November PBR included several ad hoc tax expenditures such as the more favorable treatment of capital gains, additional tax concessions (e.g., for R\&D), and investment allowances for small and medium sized enterprises and free TV licenses for older people. Staff stressed that a neutral and stable tax system remains the best means to increase efficiency and improve resource allocation

\section{Under the fiscal framework, increased transparency is an important means by} which to enhance accountability and improve the quality of public sector decision making. The United Kingdom has a generally high level of fiscal transparency by international standards. ${ }^{15}$ And transparency has been increased in the last year by additional efforts, including the publication of documents clarifying the effects of the business cycle on the budget and explaining different methodologies for analyzing the stance of fiscal policy; a fuller

\footnotetext{
${ }^{14}$ Since capital charges would compete with other current spending, departments would have a strong incentive to scrutinize new investment projects carefully and to treat private funancing initiatives (PFIs) on an equal footing. Under PFIs-which are public investment projects partly funded by private resources-the private investor typically charges a service fee which is included as current spending in the budget. With resource accounting, direct public investment will similarly incur a current budget cost through the assessment of capital charges.

${ }^{15}$ See the Experimental Report on Transparency Practices-United Kingdom, (EBS/99/34, Supplement 1, March 23,1999). As noted in the report, the United Kingdom meets or exceeds the IMF's Code of Good Practices on Fiscal Transparency.
} 
reporting of tax expenditures in budget documents; and improvements in statistical releases. The mission welcomed these improvements to transparency, particularly the enhancements made to the November Pre Budget Report documents. Nevertheless, staff noted, as have many private sector analysts, that there was scope for further improvements in the area of budget reporting. Most notably, the absence of regular Treasury reports analyzing fiscal performance during the year in relation to expectations in the budget hampered the public's assessment of fiscal developments on an ongoing basis, ${ }^{16}$ while the lack of standardized tables and presentational conventions made it difficult to compare annual budgets from year-to-year. Transparency would be much improved by the publication, as in some other industrialized countries, of regular (e.g., quarterly) Treasury reports analyzing budget execution and fiscal developments in relation to original budget plans; and the inclusion in the main budget documents of a statistical supplement with detailed historical and forward-looking tables based on a standardized accounting convention and consistent from year to year.

\section{LONGER-TERM STRUCTURAL ISSUES AND POLICIES}

29. With the economy seemingly set on a course of sustainable growth, low inflation, and reasonably high levels of resource utilization, policies have increasingly focused on achieving long-term goals, namely: a more equitable sharing of economic gains, particularly through the alleviation of poverty and inroads into long-term unemployment; pension reform; closing the sizeable productivity gap, measured by output per worker, between the United Kingdom and other major industrial countries; and strengthening the structural underpinnings of the economy, in part with a view to clarifying the implications of any eventual decision whether to join EMU.

\section{A. Policies for an Efficient and Fair Labor Market}

30. The government's welfare and labor market reforms are strongly focused on enhancing incentives to work and alleviating poverty by reducing the number of jobless households, but the effects on labor supply are uncertain, particularly in the short run. The reforms comprise three main elements: (i) New Deal for Young People and other active labor market policies which are still in their early stages; (ii) the Working Families Tax Credit (WFTC) and other changes to the tax and benefit system, including the tightening of the disability benefits regime; and (iii) the national minimum wage (Box 4). ${ }^{17}$

${ }^{16}$ The Office of National Statistics publishes monthly data on fiscal outcomes on the same accounting basis as a fairly aggregate table in the budget. However, these data are difficult to interpret against the annual budget projections without more detailed analysis from the Treasury of expected revenue and expenditure patterns during the year.

${ }^{17}$ For a fuller discussion of these reforms, see Selected Issues paper on "Welfare and Labor Market Reform in the United Kingdom: Evidence from International Experience". 
31. The initial results of the New Deal for Young People have been encouraging, although it is too early to say whether these are due to the program or to the macroeconomic performance. The program is compulsory for 18-24 year olds who have been unemployed for six months or more, with almost half finding employment and most of the others taking the education and training option. But it is not yet clear how permanent or large the employment effects will eventually be given the cyclically strong economy and the fact that participants can, in principle, keep renewing any of the four options indefinitely as long as they cooperate with Employment Service and continue an active search for unsubsidized employment. The Government has recently outlined plans to expand the New Deal for groups over 25 years of age. The authorities agreed that progress is likely to prove more challenging and costly as the program is expanded to this larger group of older unemployed or inactive workers. The role of the Employment Service would need to evolve from that of simply placing workers into vacancies to enhancing the employability of those seeking to leave welfare. A complementary policy to the New Deals would thus be to enhance the quality and availability of relevant technical and vocational training.

32. The WFTC is at the center of the reforms to the tax and benefit system. While it has reduced the net marginal effective rate of taxation and provides a strong incentive for labor force participation by one member of a household, it also implies a substantial disincentive for a second eamer. This reflects the fact that in the United Kingdom labor market inactivity and child poverty are concentrated in households with no employed working age adult. ${ }^{18}$ Policies aimed at moving at least one of the adults in such households into employment could bring substantial long-term benefits by breaking the intergenerational pattern of joblessness that results from children growing up in households in which neither parent has ever been employed. However, in the short run, labor supply and productivity gains from the reforms are likely to be limited since workers emerging from welfare rolls are likely to have low productivity and some current second earners may leave the work force (see Box 4). Scope remains for further improving work incentives by reducing the still very high rates of marginal effective taxation at the low end of the income distribution due to multiple benefit withdrawals. $^{19}$

33. The national minimum wage (NMW), introduced in April 1999, is also intended to increase the returns to work of the unskilled, and does not so far appear to have had significant negative effects on employment. The NMW is set at a relatively low level in comparison with other European countries (about 40 percent of median wages). The

\footnotetext{
${ }^{18}$ In 1998, 19 percent of children in the United Kingdom were in workless households. Comparable figures are some 5 percent for Germany; 10 percent for France and Spain; and 11-12 percent for Belgium.

${ }^{19}$ The trade-offs involved in this regard between poverty alleviation, work incentives, and budgetary costs are discussed in greater detail in the Selected Issues paper.
} 
authorities noted that the NMW had helped arrest the observed widening of the income distribution, with no appreciable negative employment effects. Staff pointed out that the NMW had been introduced at a time of unusually strong economic expansion, and hence the appropriateness of its level - and its employment effects-could not be fully assessed until after an economic cycle had been completed. It would be important therefore to maintain the NMW and the lower rate for youth and trainees at their present levels until such a time.

\section{B. Pension Reform}

\section{Recent Government proposals on pension reform are aimed at increasing the} public pension benefits of the lowest paid and bolstering the role of privately funded pensions for the rest. A major advantage of the U.K.'s present pension system is that it is largely private and funded, with a limited future fiscal burden stemming from demographic pressures. However, the Government considers that the present system does not provide an adequate social safety net for about a quarter of the labor force and that the level of benefits provided to those who are covered could, in time, turn out to be insufficient for low-income groups. To address these concerns, the Government has proposed reforms that would essentially raise public pension benefits for the lowest income earners and shift other uncovered groups to privately funded pension schemes (see Annex I). Staff questioned whether the latter option would be feasible given that the charges associated with privatelyprovided pensions have so far made these schemes unattractive for groups with low levels of income and volatile employment histories. The authorities explained that they were negotiating with private pension providers on administrative charges to be levied on these pensions and were confident that an agreement could be obtained that would make such pensions mutually attractive to both the target group and private pension providers. As of the time of writing, the authorities had not yet finalized their plans. The staff's main concerns would be that these limit both any associated increase in the cost of hiring the unskilled and the risks to the fiscal accounts stemming from higher public pension benefits and from an only partially successful attempt at shifting pension liabilities for the less well paid to the private sector.

\section{Closing the Productivity Gap: Investment, Competition, Innovation and Regulation}

35. With the economy's macroeconomic performance having improved, the authorities have increasingly focused on the policies that might help narrow the United Kingdom's productivity gap with other major industrialized countries. While productivity level comparisons are fraught with well-known measurement difficulties (particularly with regard to the capital stock), the available evidence points to substantial shortfalls in the U.K.'s labor productivity that seem to reflect mainly sizeable gaps in its human and physical capital stock (both public and private) and, to a lesser extent, total factor 
productivity (Table 5) ${ }^{20}$ Concerns in this respect have been accentuated of late by the fact that labor productivity, which had increased quite rapidly during the first half of the 1990s, has slowed down since then to about 1 percent per annum (Figure 12). ${ }^{21}$

\section{Partly in response to these considerations, the authorities' strategy features} sizeable increases in both physical and human capital investment. The 1998 Comprehensive Spending Review allocated sizeable spending increases for education and for public investment which had fallen to quite low levels. Moreover, the Government's fiscal strategy - particularly the "golden rule"-is partly aimed at protecting planned increases in public investment from budget cuts or pressures from higher current spending. The mission welcomed these steps, but went on to question whether, with the economy now seemingly set to operate more nearly at potential, there was not also a case for crowding in private investment by tightening the fiscal rules, e.g. by

shifting from a golden to a fiscal balance rule (over the cycle). Admittedly, those investments could be financed with foreign savings instead, through larger current account deficits. However, this had not proven to be a very safe course historically, and the more prudent course might be to raise domestic-in practice, public-savings over the medium term. The merits of at least considering such a policy seemed clear from the U.K.' 's relatively low rates of private saving and the fact that private investment has tended to move in tandem with the fiscal balance in recent years

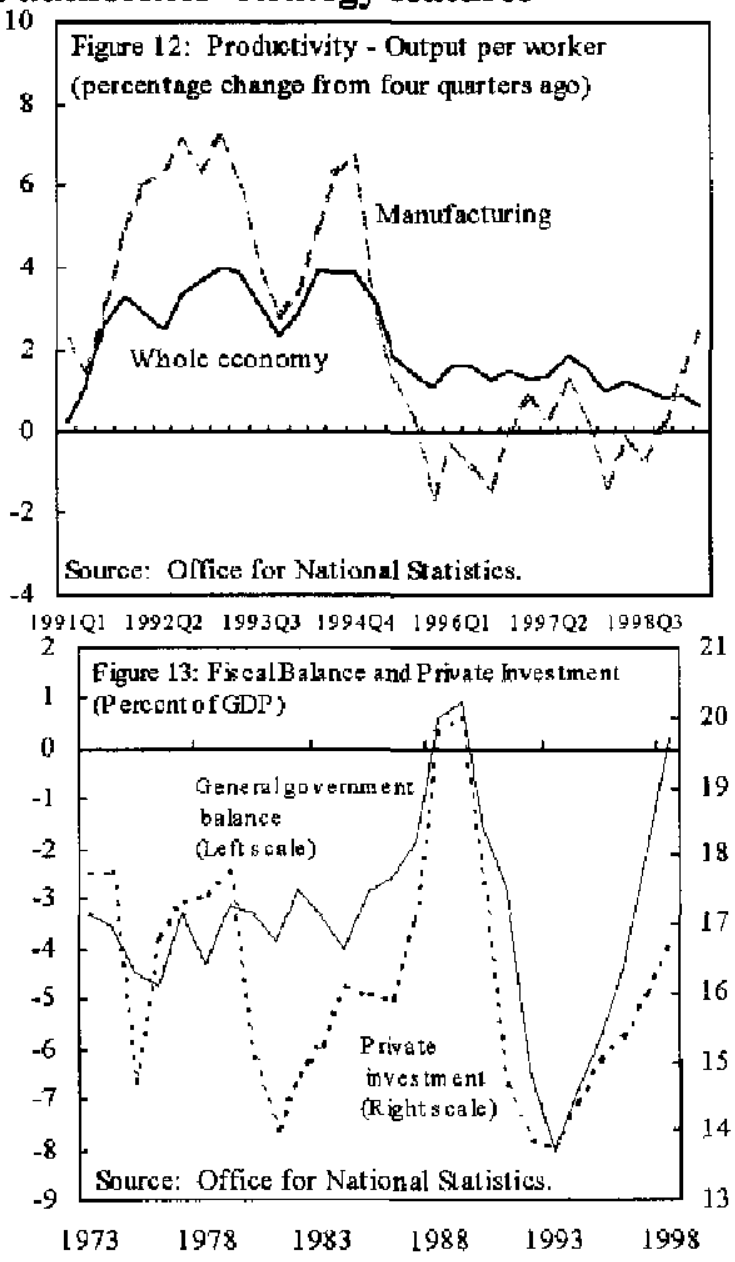

20 An influential recent study is by M. O'Mahoney, Britain's Productivity Performance, 1950-96: an International Perspective, National Institute of Economic Research, 1999. Treasury officials indicated that the result of this study accorded with their own analysis.

${ }^{21}$ The reasons for the productivity slowdown in the late $1990 \mathrm{~s}$ are not well-understood. It partly reflects a three-year collapse in manufacturing productivity due mainly to cyclical factors as well as the unusually strong and sustained employment growth, particularly in services. However, it is notable that labor productivity growth has been robust in countries such as the United States and Canada which also experienced strong employment growth in the 1990s 
(Figure 13). Given the increasing constraints on raising taxes, in practice, this implied a need to further restrain current spending, all the more so given the need to sustain, and possibly increase, some productive current expenditures, such as education. The authorities noted that it was difficult to know the level of the optimal capital stock for the United Kingdom, ${ }^{22}$ but the current level was seen as surely below it, even after some years of strong investment growth. While the Government was seeking to further improve the climate for private investment (for instance, by creating a more stable macroeconomic environment and through increased competition and deregulation-see below), they were also persuaded of the importance of complementary increases in public (especially transport) and human capital investment. In this regard they did not feel that a tightening of the fiscal rules was needed to crowd in private investment since some widening of the current account deficit would not be a problem if it corresponded to investment in productive assets.

\section{The Government's strategy also places considerable emphasis on competition,} regulation, and innovation as drivers of productivity growth. ${ }^{23}$ The Competition Act of 1998, which comes into force in March 2000, significantly enhances the powers of the Office of Fair Trading (OFT) to tackle anti-competitive practices and abuses of a dominant market position. It also strengthens the independence of the OFT and introduces strong penalties for firms which breach prohibitions in the Act. Significant deregulation is already occurring in utilities (particularly telecommunications, gas, and electricity), while a Utilities Reform Bill will confer on the energy, water, and telecommunications regulators a primary duty to advance consumer interest through competition wherever possible and appropriate. The Government has also taken measures to encourage enterprise and innovation; undertaking a review of the corporate insolvency regime with a view to making it more amenable to corporate rescue; and improving the regional planning system, particularly to help promote the clustering of firms (to encourage knowledge spillovers).

${ }^{22}$ The large differences between estimates of capital intensity for the United States and Germany in Table 5 suggest that desirable levels may vary considerably across countries depending, for instance, on their labor market structures or the sources of their comparative advantages.

${ }^{23}$ This view accords with some industry-level assessments of factors explaining the U.K.'s weak productivity performance. One such study evaluating the U.K.'s comparative performance in six key product markets (automobiles, food processing, food retailing, hotels, software and telecommunications), finds that inadequate domestic and international competition and product market regulation (particularly price constraints and land use regulations) are key reasons behind the low levels of private investment and nonimplementation of global best practices. N. Lovegrove et al. "Why is Labor Productivity in the United Kingdom so Low?" McKinsey Global Institute Anthology, 1998. 
38. An efficient and stable capital market is also essential for robust investment and productivity growth. In this regard, the Bank of England has been given responsibility for the overall stability of the financial system in the face of generalized domestic and international risks, with a particular responsibility for ensuring the smooth operation of the payments system. ${ }^{24}$ Supervision, on the other hand, has been devolved to the Financial Services Authority (FSA), the single regulator established in 1998, which has been charged with ensuring the effective and efficient regulation of the increasingly integrated financial services industry. ${ }^{25}$ In January this year, the FSA announced a radical new risk-based strategy for the future regulation of the U.K.'s financial services sector designed to enhance consumer protection and reduce the regulatory burden on firms. ${ }^{26}$ The new regulatory approach will be proactive and preventive, with less emphasis being given to routine monitoring, particularly of small low-risk firms, and more to identifying each year the most important risks facing firms, markets, and consumers and to translating these into regulatory themes for priority attention by managers and regulators. The ain is to create an environment which encourages firms to manage their own risks better and thereby reduce the burden of regulation.

\section{Possible Entry into EMU}

39. Entry into EMU is a key policy decision for the United Kingdom, and one that is correspondingly controversial. The Government has made clear that the determining factor on whether the United Kingdom should join is the national economic interest. To this end it has identified five economic tests that must be met to proceed with a decision to enter (Box 5). Since it is generally acknowledged that at least some of these tests are unlikely to be met in the near term--particularly that of having achieved sustainable and settled convergence - a decision on joining is not anticipated before the next Parliament. Nevertheless, in order to have a genuine choice in the future, the Government has been undertaking preparations for entry ("prepare and decide"). In February 1999, a National Changeover Plan for the adoption of the euro was published which aims to ensure that procedural aspects of joining are anticipated and addressed accordingly.

${ }^{24}$ The Bank's Financial Stability Review provides periodic assessments and analyses in its areas of responsibility.

${ }^{25}$ The framework for cooperation between HM Treasury, the Bank of England, and the Financial Services Authority in the area of financial stability has been set out in an October 1997 Memorandum of Understanding. For a discussion of this framework and a review of the regulatory structure established with the creation of the FSA, see "The Financial Services Authority: Structure, Mandate, and Policy Issues" in United Kingdom - Selected Issues (SM/99/43 February 17, 1999). The Financial Services and Markets Bill, which lays the statutory basis for the FSA, was introduced to Parliament in June of 1999.

${ }^{26}$ A New Regulator for the New Millenium, The Financial Services Authority, January 2000. 
40. The public debate on whether the United Kingdom should join the euro is mostly political, but there are a number of economic arguments for and against entry (see Box 5) ${ }^{27}$ Among these, those most often mentioned on the plus side are the opportunities for enhanced investment and growth due to lower transaction costs, greater transparency of relative prices, increased trade and the elimination of a major source of exchange risk-a particular consideration for the United Kingdom given the exchange rate volatility generated by the large capital account flows. On the debit side, there are the potential costs associated with having to adjust to asymmetric shocks or asynchronous business cycles without recourse to an independent monetary policy. Balancing these considerations from a long-run perspective will be difficult under any circumstance, all the more so given the strong priors often brought into such matters. But it is even harder to discern these matters at present because of the differences in the U.K.'s and the euro area's relative cyclical positions. There is some prospect that this divergence will diminish over the next few years. ${ }^{28}$ In the same vein, staff analysis suggests that wage flexibility in the United Kingdom appears to have increased significantly over the past decade (Box 6), suggesting that the potential costs of joining EMU may have diminished. ${ }^{29}$ Thus, while uncertainties will presumably remain, there is some prospect that the issues may be easier to discern in time.

\section{STAFF APPRAISAL}

41. The performance of the U.K, economy continues to be impressive. Real growth has been strong since the recovery from the steep recession of 1990-92 and both unemployment and inflation have declined steadily from their peaks earlier last decade. The economy has weathered the shock from the slowing of global trade in late 1998 better than expected, with output returning only briefly to potential. Growth is resuming at a clip, private consumption is buoyant, and exports are staging a recovery. While the strength of sterling is a source of uncertainty, this risk seems manageable. Hence, given the authorities' policy frameworks and their track record of skillfully managing policies within those frameworks, there is good reason to expect sustained growth and low inflation to continue.

42. The immediate challenge is to prevent overheating. The resumption in growth is taking place on the back of an economy that is already at or close to full employment and the risks are mainly on the upside. The near-term prospects for inflation remain subdued due to temporary factors and possible structural shifts in the economy. However, the mitigating

\footnotetext{
${ }^{27}$ See Selected Issues paper on "The Costs and Benefits of Joining EMU."

${ }^{28}$ See "United Kingdom Business Cycle and EMU Entry" in United Kingdom-Selected Issues (SM/99/43 February 17, 1999) which suggests that the U.K.'s cyclical fluctuations have been associated with unstable monetary conditions in the past.
}

${ }^{29}$ See Selected Issues paper on "Wage Flexibility and EMU". 
effects on prices from these factors are likely to wear out, allowing resource utilization pressures to predominate over time.

\section{Given this risk, policies-in the first stance, monetary policy-will need to} tighten over the coming year. The record of the MPC in taking prompt, forward-looking action as circumstance requires is encouraging, and we, like the market, expect that policy rate increases will be forthcoming. Given cyclical considerations and the strong real exchange rate, fiscal policy will need to be supportive. The cautious fiscal stance and the cyclical strength of the economy are likely to result in a stronger fiscal balance in FY 1999/2000 than anticipated in last year's budget. It is important that the March 2000 budget not use the margins built up by the overperformance of last year. Indeed, just as the framework provides scope for a discretionary easing of policy in the event of a downturn, developments (on the exchange rate, for instance) could be such as to warrant considering a discretionary tightening. It is also important to consolidate the credibility of the government's newlyestablished fiscal framework by abiding by the existing three-year revenue and expenditure plans.

\section{The U.K.'s remarkable economic performance of recent years is in part due to} the strengthening of the policy frameworks. Not only have these frameworks helped foster sound macroeconomic and structural policies, but through their emphasis on transparency and accountability in public decision making, they have also given a high degree of credibility to policies and boosted private sector confidence. An early start on structural reforms, particularly in labor markets, has also allowed the supply side of the economy to respond flexibly.

45. The inflation targeting framework has again proven its worth. The sharp decline in inflation expectations since its introduction speaks to its credibility. The forward-looking, pre-emptive aspects of the U.K.'s approach are particularly commendable. However, we would see merit to embedding that forward-looking dimension even more deeply into the forecasting process by building in a view about how policy might react to developments if they were in line with those envisaged in the forecast. Internally, such an extension would provide a helpful framework within which to clarify points of agreement and disagreement among the Members of the MPC and to think through policy options more dynamically and systematically. Admittedly, this would not be easy, particularly for individually accountable Committee Members: it would require them to agree on some of the mainsprings of policyhow fast to eliminate deviations in inflation at least cost to other, albeit secondary, objectives of policy such as maintaining reasonably full employment. Externally, the MPC clearly could not sign on to such an extension of the framework until the Members were comfortable that it represented both a reasonably robust middle ground and that its incorporation into the published forecast did not run undue risks of misleading markets and the public. The payoff to being able to be transparent in this regard could be significant, and worth the effort, however. In the first instance, it would bring the forecasting process into line with expectations regarding the inflation targeting framework - that of aiming for a smooth and timely convergence of inflation to the target. More fundamentally, it could contribute to reduce 
uncertainty and improve economic performance yet further. Be this as it may, transparency concerns should not inhibit progress in improving the forecasting framework itself.

46. The medium-term orientation of the fiscal framework provides a measure of assurance that the public finances will be managed prudently on a sustained basis. However, given past consolidation and present budget plans, the current fiscal rules are not particularly binding and leave scope for sizeable future spending initiatives. Both from this perspective and with a view to boosting productivity growth (see below), a tighter fiscal rule-for instance, overail balance over the cycle-may be more appropriate. The efficiency gains and improvements in public resource allocation that are becoming evident are encouraging, but it will be important to guard against increased resort to indirect means of funding new initiatives-particularly through tax expenditures. Fiscal transparency is high by international standards, but could be further strengthened by improvements in the area of budget reporting.

47. With macroeconomic policies and frameworks set to deliver sustained growth and low inflation, longer-term policies have shifted towards achieving greater equity and strengthening productivity. In this context, the Government's recent welfare and labor market reforms are appropriately set on strengthening incentives to work. Although it is too soon to evaluate their impact, early indications are encouraging. These programs, particularly the New Deal and the National Minimum Wage, have been introduced at a time of strong economic performance and their effects on employment would need to be assessed during a cyclical downturn as well. Until such time, the NMW, including the lower rate for youth and trainees, should be maintained at current levels in nominal terms.

48. The pension reform is intended to increase the savings and coverage of those who at present are not adequately covered and to bolster the role of the private pension system in providing pension coverage for all but the lowest paid. The fiscal burden would need to be carefully assessed given the risk that the expanded entitlements and coverage of the public pension system could substantially enlarge future fiscal liabilities. It would also be important to ensure that the contributions and charges associated with the extension of private pension coverage do not increase the cost of employing low-income workers.

49. Closing the productivity gap vis-a-vis other major industrialized countries is an important long-term challenge. This would require increased private and public investment rates on a sustained basis. A key question is how such increases in total investment could be made to happen and how they should be funded. Given the already high level of the real exchange rate and the risks of relying excessively on foreign savings, boosting domestic savings seems to be a prudent option. The most effective means to achieve this would be to increase public saving. While we support the intention underlying the current fiscal rules of protecting public investment from budget squeezes, there may be a case for strengthening the fiscal rules beyond the golden rule to require higher public savings and fiscal balance over the cycle. These issues and possibilities for greater prioritization within current spending towards 
productive expenditures such as education should be assessed during this year's spending review.

50. The recent steps to increase competition, encourage innovation, and put in place appropriate regulatory regimes are commendable. The role of the Financial Services Authority in regulating the increasingly integrated and complex financial services industry is a key element in this regard as is the role of the Bank of England in ensuring the overall stability of the financial system. The $F S A$ 's intention to periodically identify the main sources of system-wide prudential risks and thereby alleviate some of the deadweight losses associated with on-going moritoring and supervision is interesting and will be reviewed in next year's report.

51. Entry into EMU remains a key medium-term decision for the United Kingdom. The government has adopted an approach of preparing under this Parliament and taking the decision to join later when the national economic interest in doing so is clear. Although many factors will influence the decision whether to join, an overriding economic case for or against entry camot be made at this moment. Many of the uncertainties are likely to lessen over time, however.

52. The Government's efforts to relieve the debt burden of poor countries and their commitment to reverse the downward trend in aid spending are commendable. We encourage them to accelerate progress toward the U.N. target for overseas aid spending of 0.7 percent of GNP from the 1999 level of 0.27 percent of GNP.

53. The United Kingdom publishes data on a sufficiently timely and comprehensive basis to permit effective surveillance (Appendix III). The authorities have indicated their intention to participate in the pilot project for the publication of staff reports. It is proposed that the next Article IV consultation with the United Kingdom will be held on the standard 12-month cycle. 


\section{Box 1. The Monetary Policy Framework}

In May 1997, the Bank of England was granted operational independence with the primary statutory objective of pursuing price stability-defined by the Chancellor as a $2 \frac{1}{3}$ percent target for RPIX inflation at all timcs. The Bank also has a statutory obligation - subject to its primary objective—of supporting the government's economic policy, including its objectives for growth and employment.

The Bank's Monetary Policy Committee (MPC) is accountable to the Government for delivering on the Bank's remit. The MPC is a committee of nine independent experts, five of whom are staff of the Bank of England (including the Governor, who is Chairnan of the MPC) and four are external members appointed by the Chancellor, drawn from academia, finance, and other fields and chosen for their professional expertise as ccononists. Each member is expected to be individually accountable for his or her policy actions.

Recognizing that actual inflation can deviate from the target due to exogenous shocks and disturbances, and that attempts to keep inflation to target in these circumstances may cause undesirable volatility in output, the MPC is obliged to send an open letter to the Chancellor if current inflation moves away from the target by more than one percentage point in either direction. Given lags in the transmission of monetary policy, the MPC has operationalized its remit as targeting an inflation rate of $2 \frac{1}{2}$ percent two years hence. The target is symmetric in that the MPC would respond just as vigorously to a prospective undershooting of the target and as to a prospective overshooting. The symmetry of the target goes some way in ensuring that monetary policy supports the Government's objective of high and stable levels of growth and employment since it gives the MPC as much incentive to lower interest rates if outpul slips below potential-and inflation threatens to undershoot the target (two years hence)-as to raise rates in the opposite situation,

The MPC's policy meetings are held on a regular schedule (the first week of every month) and are followed, two weeks later, by the publication of the minutes of the meetings. Although the minutes do not attribute views to individual Committee nembers, they record the vote of individual members on the monthly interest rate decision-a device which reinforces the individual accountability of Committee members. As discussed in the last Article IV staff report (SM/99/36 February 10, 1999), these minutes provide a highly informative guide to the debate within the Conmittee as well as a rationale for the monthly rate decisions, and have been key in enhancing the transparency of monetary policy actions.

A central feature of the MPC's decision making process is the inflation forecast which is formulated by the Conmittee members themselves, with the role of the Bank of England staff limited to one of executing the forecast on the Committee's instructions. The forecast is published every quarter in the Inflation Report. The Bank is held accountable to the public at large through the publication of the In/lation Report and the minutes of the MPC meetings. It is also accountable to Parliament through regular reports and evidence given to the Treasury Select Committee. 


\section{Box 2. The Constant Interest Rate Assumption and Alternatives}

Several countries, including the United Kingdom, that have adopted inflation targeting frameworks have, in practice, taken the approach of targeting an inflation forecast, recognizing that changes in monetary policy are capable of influencing inflation only with a lag. The analysis of how inflation targeting should be implemented and policy decisions explained to the public has focusod on different forms of monetary policy rules or policy reaction functions. There is wide recognition that it would be dangerous to adhere rigidly to any mechanical policy rule and the practice of inflation targeting has been described as involving "constrained discretion". At the same time, policy makers have found quantitative frameworks can be important in helping them structure their thinking, and monetary policy rules play a central role as benchmarks or guidelines that make those quantitative frameworks internally consistent. In this regard, the Inflation Report features inflation forecasts that assume an umchanged policy rate over the two-year horizon equal to that most recently set by the MPC. The forecasts show inflation 8 quarters out at or very near the target rate.

Simulations run on the staff's quarterly model of the U.K. economy illustrate some of the potential problems with the MPC's constant interest rate assumption and forecasting process. The figures below show the quarter-to-quarter behavior of the policy rate, rate of inflation, and the output gap following an unanticipated increasc in aggregate demand and assuming no further shocks. Figure 2.1 shows the increase in the policy rate under the MPC's forecasting assumption-where the interest rate is held constant at its new level over the 8 -quarter horizon--and the path inflation would follow given the objective of bringing inflation down to the target in 8 quarters. Consistent with the Bank of England's practice, the interest rate is assumed to follow a Taylor rule after the 8-quarter horizon. ${ }^{2}$

Note that this assumption reduces inflation back to target in 8 quarters, but pushes inflation below the target thereafter reflecting changing real monetary conditions. Thus the intent of holding the interest rate constant for 8 quarters would not remain consistent with the policy objective because in the second period, the MPC would find that the objective of hitting the $2 \frac{1}{2}$ percent target under a constant interest rate would call for a reduction in the level of the "constant" interest rate. Similarly, as shown in Figure 2.2, further gradual reduction in the policy rate would be called for in the subsequent quarters, so that the intent of holding the interest rate constant for 8 quarters would not be time consistent. Moreover, il would actually take much longer than 8 quarters to get inflation back to target, so that the MPC's objective cannot be met under this framework.
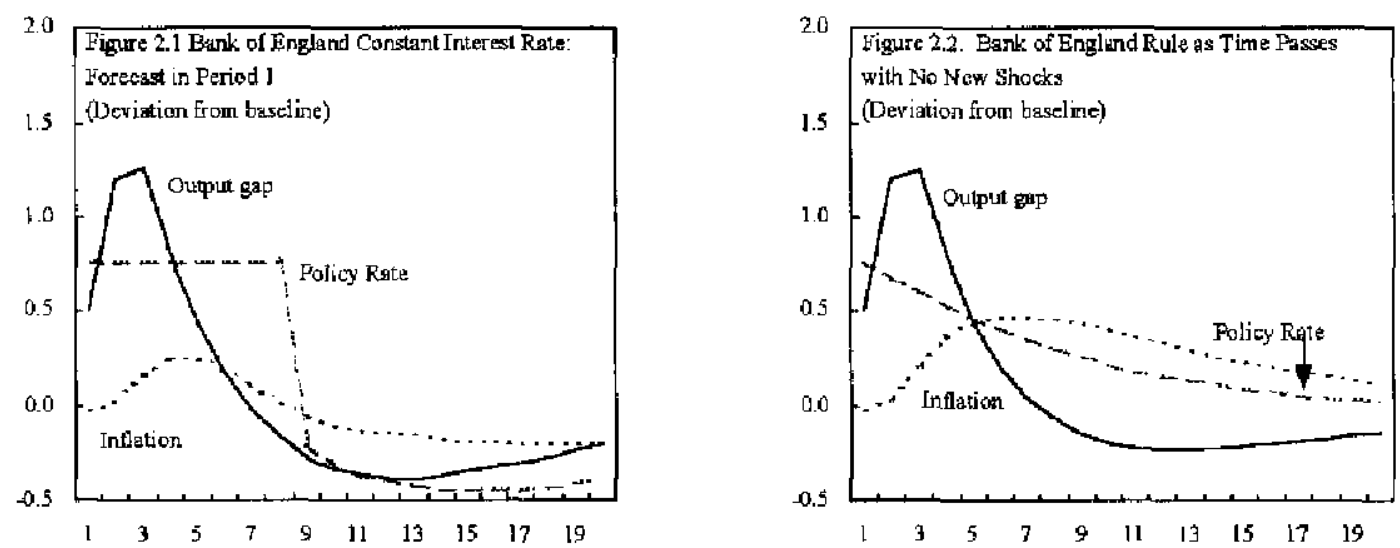

For comparison, Figures 2.3 and 2.4 show the paths that the interest rate and inflation would follow under a model-consistent inflation-forecast-based (IFB) rule and a generalized Taylor nule. ${ }^{3}$ These rules are time consistent in the sense that the paths for interest rates and inflation, as time passes, are consistent with the forecast paths. Both of these alternative rules would call for a much sharper near-term increase in the policy rate than the Bank of England's forecasting assumption and would generate the real monetary conditions needed to bring the inflation rate much closer to the target level of $2 \frac{\mathrm{b} / 2}{2}$ percent within 8 quarters. 

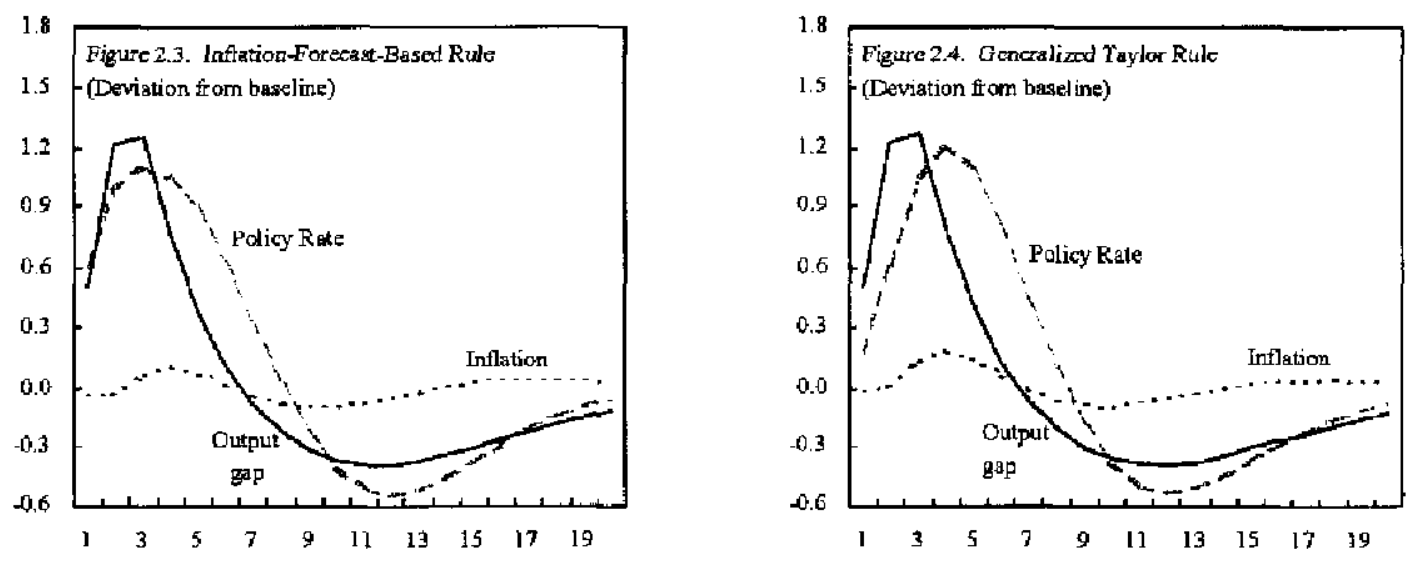

A more consistent and less constrained approach to the elaboration of the MPC's forecast-with regard to the interest rate assumption and the forecast horizon-would be useful. In particular, as illustrated by the above simulations, it would be helpful to develop a policy reaction function that would gererate a timeconsistent, flexible interest rate response according to which real monetary conditions would change during the forecast horizon as needed for inflation to converge on the target. The altcrnative inflation forecast presented in the Inflation Report based on estimated current market interest rate expectations does not meet this point since that path is imposed exogenously, rather than being derived endogenously within the forecast. In addition, it would be usefil to extend the forecast horizon well beyond the two-year target horizon to highlight any overshooting or undershooting problems associated with trying to achieve the target either over too short an interval of time or with an insufficiently pro-active use of interest rates.

${ }^{1}$ The issues covered in this box are discussed in greater depth in the Selected Issues paper "Issues Relating to Inflation Targeting and the Bank of England's Framework".

${ }^{2}$ Under a Taylor rule, the policy maker would adjust the official rate as a function of the most recently reported data on inflation and output (or unemployment). Other things equal, nominal interest rates are adjusted by more than any change in the inflation rate in order to affect the real interest rate, and hence real monetary conditions.

${ }^{3}$ Although the simulations reported above suggest that a Taylor nule would generate a similar path to a modelconsistent IFB rule, this reflects simplifying assumptions made with regard to the structure of the model. Because Taylor rules are basically backward looking, they have been found to perform quite poorly in nonlinear models with forward-looking expectations in comparison with model-consistent IFB rules. This is essentially because making a firm commitment to a backward-looking rule would not be effective in stabilizing inflation expectations in such models. Further details are given in the Selected Issues paper. 


\section{Box 3. The Fiscal Framework}

The present fiscal framework comprises three tiers'

(i) two fiscal rules which are defined over the business cycle-the golden rule and a debt sustainability rule. The golden rule stipulates that budget delicits cannot exceed not public sector investment (i.e., that there cannot be a deficit on the current balance) while the sustainable debt rule stipulates that net public debt should be prudent and stable as a ratio to GDP (currently interpreted as not exceeding 40 percent of GDP).

(ii) actual announced three-year budget plans, including Departmental Expenditure Limits (DELs) which set out three-year department-by-department nominal spending limits covering most discretionary current and capital expenditure (about half of total spending); and

(iii) various steps designed to cnhance efficiency and accountability, particularly with regard to public spending, including a statutory Code for Fiscal Stability that underpins the entire fiscal framework and sets out broad principlcs of fiscal management as well as requirements for the publication of budget documents; a threc-year spending review setting out departmental goals and spending priotities; and publication of departmental Public Service Agreements (PSAs) quantifying these goals and Deparimental Investment Strategy reports providing cost-benefit analyses of proposed investments.

The three-year DELs are set at the time of the spending reviews. The first such review took place in July 1998 and set out cxpenditure plans for FY1999/2000-2001/2002. The next spending review is expected to take place in 2000 and will set spending plans for FY2001/2002-2003/20004. Thus, in order to provide some continuity, the first year of the new DELs overlaps with the last year of the previous DELs. The 2000 spending review will coincide with the introduction of resource accounting in the public sector which will bring public finance accounting methods very closely in line with standard financial accounting methods used by the privatc sector.

A fuller description and discussion of the fiscal framework is given the 1998 Article IV staff report (SM/99/36, February 10, 1999). 


\section{Box 4: Recent Welfare and Labor Market Reforms}

The United Kingdom has embarked on a wide-ranging program of welfare and labor market reform, with a central goal to reduce the number of jobless households, alleviate income inequality, and break the intergenerational cycle of poverty that results from children growing up in a household with no working adult. A common feature of the programs is that they provide incentives for the cconomically inactive to enter the labor force through the use of expanded in-work bencfits - benefits that are available only to those in employment. These financial incentives are complemented by active labor market policies that provide welfare recipients with assistance in job-seeking, training and, if necessary, subsidized employment. Highlights of the individual programs are as follows:

- New Deal for Young People and New Deals for other groups, April 1998 and ongoing. Following six months in unemployment, provides a four month "gateway" period of intensive advising and monitoring, after which participants who are still unemployed must choose among the four options of: (i) full-time education or training; (ii) subsidized cmployment; (iii) participation in voluntary work; or (iv) an environmental task force Remaining passively on the unemployment role is not an option. Additional New Deal programs target groups such as the Disabled and Lone Parents, and there is also a New Deal for the long term unemployed older than 25 which is currently being extended to bring it more into line with the New Deal for 18-24 year olds.

- Working Families Tax Credit, October 1999. Provides a refundable tax credit for low earners (with children) who work a minimum of 16 hours per week, with an additional credit for 30 hours, and offers a generous subsidy for childcare expenses. Effectively guarantees an after-tax income just above $£ 200 /$ week for a working family with one child, enriching the minimum wage by 40 percent. The WFTC is expected to affect 1.4 million households, up 40 percent from the less generous Family Credit that it replaced.

- Income Tax and National Insurance Contribution reform, April 1999. Establishes a 10 percent tax band on low income earners, and reduces the basic tax rate by one percentage point to 22 percent, effective April 2000. National Insurance Contribution reform raises the starting point at which employers pay national insurance, aligns this with the personal allowance on income tax, and eliminates the previous fixed entry fee. These latter measures are aimed at reducing hiring disincentives faccd by employers.

- Disability Benefit reform, ongoing since 1995. Contribution requirements while in employment have been increased before disability coverage becomes available, and a medical test for disability has replaced the previous criterion of "employability," under which workers in industries undergoing restructuring (e.g., the coal industry in the 1980s) were often put on disability and thus out of the labor force, rather than into the unemployment roll. The medical test alone appears to have reduced the rate of entry into disability by around 30 percent. A New Deal for the Disabled provides additional resources for training and employment subsidies.

- National Minimum Wage, April 1999. Provides a $\$ 3.60$ per hour minimum wage for adult workers and a rate of $£ 3.00$ per hour for $18-21$ year olds. At introduction, this was expected to cover $8 \frac{1}{2}$ percent of labor force and result in a 0.6 percent rise in the wage bill.

These programs share many aspects of efforts that have proved frutful in other countries, although adapted to U.K circumstances. For example, the WFTC is similar to the Eamed Income Tax Credit in the United States, which is estimated to account for as much as 60 percent of the increased employinent of single women with children during 1984-1996, though at the risk of providing disincentives for second wage earners. The intensive assistance provided under the New Deals is likewise similar to programs in the United States, especially the pioneering cffort in Wisconsin. However, a notable difference between the U.K. and U.S. approaches is that in the United Kingdom, the New Deal for Young People does not cut off participants from welfare as long as they participate in the program and continue an active job scarch for unsubsidized employment. Efforts to reduce the incidence of disability are in contrast with the approach taken in some other European countries, where older displaced workers are encouraged to retire rather than to compete for jobs with less experienced workers.

It is too early for an overall evaluation of the welfare and labor market reforms, particularly whether the impact on labor supply will be of a permanent nature. There are promising initial signs, with somc 350,000 youth under 25 years estimated to have joined the New Deal for Young People and 145,000 to have found 
(mainly unsubsidized) employment by October 1999. More people than anticipated have taken the education and training option rather than the subsidized job option, thus lowering fiscal costs below initial projections. It is still unclear whether this has been due to the lack of demand by employers (because the subsidy is not adequate) or a lack of interest in subsidized jobs by the unemployed. Feedback from employers suggest that many who were hired through the program and subsequently laid off lacked basic employability skills (e.g., reliability, punctuality). This has led to some rethinking by the authorities on the type of training programs that neect to be provided.

The Working Families Tax Credit (WFTC) provides an incentive for welfare recipients to enter the labor force by topping off after-tax income for those working 16 and 30 hours, although this is offset to some extent by the withdrawal of other means-tested benefits (for instance, the 65 percent withdrawal of housing benefits). The impact of the WFTC is illustraled in the charts below, which show the after-tax weekly income for a household with two adults and one child (Figure 4.1), and the marginal rate of taxation faced by this household (Figure 4.2). The calculations include the effects of the WTTC, unemployment benefits, income tax, national insurance contributions, and a $f 45$ weekly housing subsidy-around the median rent for public housing. For a jobless household, the incentive effects of the WFTC are unambiguously positive for one adult to enter the labor force for a minimum of 16 hours per week, as household income jumps considerably at this point even with the withdrawal of other benefits, and then rises again at 30 hours. However, as Figure 4.2 shows, the positive incentive effects are concentrated at 16 and 30 hours, with quite steep marginal tax rates for additional hours.
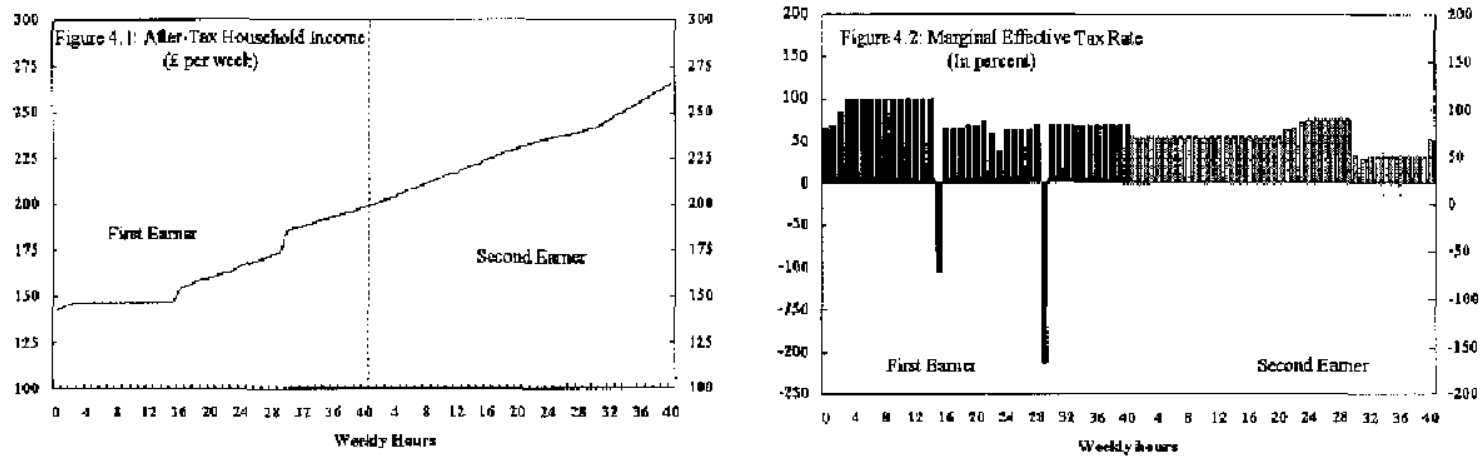

The WFTC leads to a two-fold disincentive for labor force participation by the second earner. First, the withdrawal of WFTC benefits paid to the houschold means that the second adult considering even part-time work faces a 55 percent effective tax rate for fewer than 20 hours of work (even without having to pay income tax or national insurance contributions). Second, the demand for leisure typically rises with income, so that the increase in household income from WFTC benefits accrued on the basis of the first earner would be expected to lead the second partner to work less in the first place.

The experience of the United States with the Earned Income Tax Credit (EITC) suggests that concerns about disincentive effects on second earners may be valid. The EITC has been found to have a statistically significant positive effect on labor force participation of low-income single women, but with the offsetting effect for overall labor șupply of a small reduction in hours worked and a decrease in labor force participation by married women. ${ }^{1}$ Preliminary research on the WFTC suggests an ovcrall net increase in labor force participation of only around 45,000 workers, compared to total U.K. employment of around 27 million. ${ }^{2}$

'Nada Eissa and Jeffrey B. Liebman, "Labor Supply Response to the Earned Income Tax Credit," Quarterly Journal of Economics, vol 112 no. 2, pp. 605-637, May; 1996. Nada Eissa and Hilary Williamson Hoynes, "The Earned Income Tax Credit and Labor Supply: Married Couple," NBER Working Paper 6856, December 1998; and Bnice D. Meyer and Dan T. Rosenbaum, "Welfare, the Earned Income Tax Credit, and the Labor Supply of Single Mothers," NBER Working Paper 7363, September 1999.

${ }^{2}$ Richard Blundell et. al., "The Labour Market Impact of the Working Families Tax Credit," Institute for Fiscal Studies mimeo, October 1999 


\section{Box 5: Costs and Benefits of Joining EMU}

The U.K. government decided against joining the euro on its launching on January 1, 1999. Instead, the government adopted the view that while it supported, in principle, joining the single currency at some time in the future, the decision to join would be made when it is clearly and unambiguously in the national economic interest to do so. To this end, the Chancellor announced five criteria or "tests": (i) business cycles and economic structures in the U.K. should be compatible with those of the euro area; (ii) there should be sufficient flexibility to deal with specific problems that may arise; and in addition, joining EMU should have positive effects on (iii) inward long-term investment; (iv) competitiveness of the U.K. financial services sector; and (v) job creation and economic growth. When the government decides these criteria have been met, the decision to join would be subject to a national referendum.

The debate on the issue of U.K, membcrship in EMU has, not surprisingly, intertwined economic and funancial arguments with political and institutional ones. The economic arguments on the issue are typically cast in terms of the theory of optimal currency areas (TOCA), which aims to evaluale the costs and benefits from creating or joining a common currency area ${ }^{1}$ This theory suggests that joining a monetary union is beneficial if the gains stemming from lower transaction costs and exchange risk and greater transparency of relative prices exceed the additional costs of adjusting to asymmetric shocks and asynchronous business cycles incurred by the loss of monetary and exchange rate policy instruments. The more an economy is integrated with the intended currency area, the lower are the costs and the higher the benefits of joining. Some of the considerations suggested by the TOCA can be recognized in the "five tests" formulated by the Chancellor. Perhaps the topics that have attracted most research are the measurement of the synchronicity between the U.K. business cycle and those of the main economies in the euro area and the degree of asymmetry of demand and supply shocks in the United Kingdom vis-à-vis the curo area. On these grounds, the United Kingdom usually appears (with other Nordic economies) outside a cluster of "core" economies centered around Germany, but closer to this core than Southern economies that joined the euro. An essential element in this assessment is the degree of wage rigidity prevailing in the United Kingdom. After an eventual loss of cxchange rate flexibility, these wage rigidities could prevent the absorption of asymmetric shocks without unacceptable costs in terms of unemployment and loss of output.

The TOCA, however, docs not cover all the relevant criteria for U.K. membership, even on purely economic grounds. This theory is typically formulated under strong assumptions of exogeneity of behavioral parameters which, in fact, can be expected to change as a reaction to policies and the institutional environment - including the decision of joining the euro. (Thus, for example, a nominal depreciation is typically assumed to translate into a real depreciation, even in the long term, magnifying the stabilization value of monetary policy and hence, the cost of joining a monetary union.) Further, the TOCA abstracts from capital mobility and capital account openness-arguably, more imponant factors than trade in determining short-term movements in exchange rates - which could turn an independent currency into a source of disruptions rather than an instrument of stability.

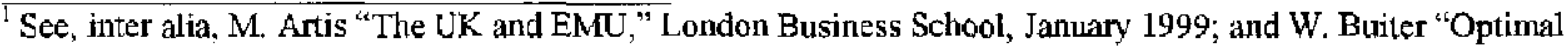
Currency Areas: Why Does the Exchange Rate Regime Matter?" Sixlh Bank of Scotland and Scottish Economic Society Annual Lecture, October 1999; P. Krugman "Policy Problems of a Monetary Union," in De Grauwe and Papademos (eds.), The European Monetary System in the 1990's, Longman, CEPS, and Bank of Greece, 1990. 


\section{Box 6. Wage Flexibility and EMU}

One of the considerations in the U.K.'s participation in EMU is the potential cost of losing the nominal exchange rate as a tool for macroeconomic stabilization in the presence of wage rigidities. If the United Kingdom suffers a demand shock under a single currency, with nominal wage inertia, unemployment is likely to emerge. The adjustment costs will be higher the less responsive real wages are to unemployment. Under a floating rate, the exchange rate could act as a shock absorber by helping relative product prices and real wages to adjust. The cost of joining EMU would thus depend in part on how flexibly wages respond to shocks.

Much of the concern over wage rigidity in the United Kingdom arises from the labor market experiences of the 1980 s. Following the reccssion in the early $1980 \mathrm{~s}$, real wages rose rapidly despite high and rising unemployment. Consistent with this, cross-country estimates of the response of aggregate real wages to unemployment showed the United Kingdom to have a high degree of real wage rigidity relative to other OECD countries. Since then, however, labor market institutions have undergone a number of changes which may have increased wage flexibility. Two changes in particular-the weakening of trade unions and the abolition of Wages Councils - are thought have had a significant impact on wage formation. ${ }^{2}$

While the effect of these changes is difficult to gauge, labor market outcomes in the 1990s have generally been consistent with grcater wage flexibility. The early 1990 s recession was followed by more moderate real wage growth and a more rapid furnaround in employment in comparison with the $1980 \mathrm{~s}$. (Figure 6.1). ${ }^{3} \mathrm{Also}$, the regional dispersion of unemployment has narrowed considerably. Moreover, estimates of the responsiyeness of aggregate real wages to unemployment show a greater degree of real wage flexibility than previously. ${ }^{4}$
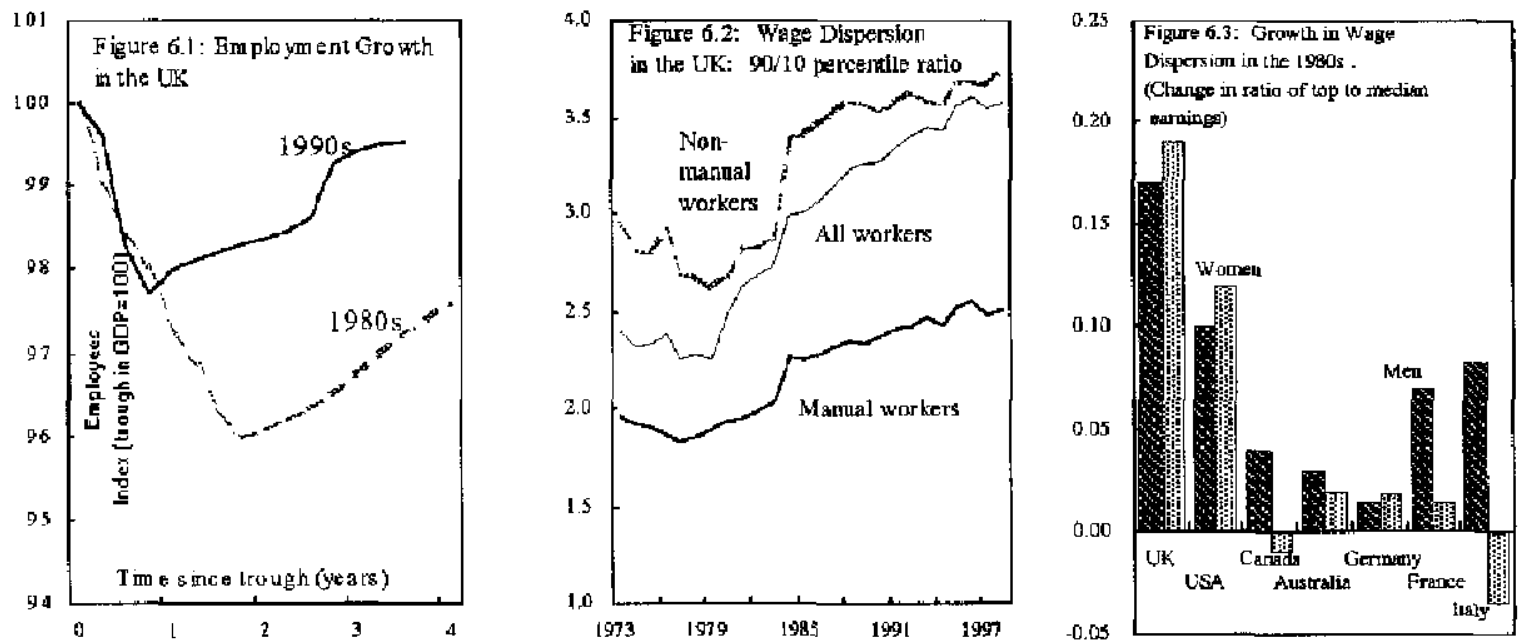

In addition to the better aggregate labor market performance, variability of wages across skills, occupations, industries, and regions has increased markedly since the 19805 ; increases have been particularly large across occupations and between skilled and unskilled workers (Figure 6.2). Greater wage dispersion is one sign that labor markets are able to rcspond flexibly to changes in relative demands for different types of workers, although it does, at the same time, raise potential concerns about equity and underscore the need to strengthen social safety nets. In this regard, although a number of countries experienced a rise in earnings inequality during the 1980 s-generally attributed to skill-biased technical change - the increase was significantly greater in the United Kingdom despite rising real wages at the bottom of the distribution (Figure 6.3). This increase has closely coincided with institutional change: wage dispersion grew much faster in the non-union sectors and in sectors not affected by Wages Council minimum wages. ${ }^{5}$ Neither the improved aggregate performance of the 1990 s, nor changes in wage dispersion provide definitive evidence of greater flexibility. However, taken together these changes are consistent with the view that institutional changes in the 1980 s have increased the flexibility of wages in response to changes in demand.

${ }^{1}$ Layard, R., S. Nickell and R. Jackman, Unemployment: Macroeconomic Performance and the Labour Market, Oxford University Press: Oxford, 1991.

${ }^{2}$ Machin, S. and S. Stewart, Trade Unions and Financial Performance, Oxford Economic Papers, 1996.

${ }^{3}$ Morgan I., "Labout Market Recoveries in the UK and Other OECD Countries" Labour Market Trends, 1996.

${ }^{4}$ Berthold, N., R. Fehn and E. Thode, "Real Wage Rigidities, Fiscal Policy, and the Stability of EMU in the Transition Phase" MF Working Paper 99/83, 1999.

"Machin, S., "The Decline of Labour Market Institutions and the Rise in Wage Inequality in Britain" Europen Economic Review, 1997. 
Table 1. United Kingdom: Selected Economic Indicators and Staff Projections

$\begin{array}{llllllll}1995 & 1996 & 1997 & 1998 & 1999 & \text { lf } & 2000 & \text { l/ }\end{array}$

Real Economy (change in percent)

\section{Rcal GDP}

Dutput gap

Domestic demand

Retail price index (excluding mortgage interest) $2 /$

Unemployment rate (claimant count, in percent) $2 /$

Unemployment rate (labor force strvey, in percent) $3 /$

Gross national saving (percent of GDP)

Gross domestic investment (percent of GDP)

Public Finance (in percent of GDP) 4/

General government balarce

Public sector balance

Public sector net debt

Money and Crodit (end-year, percent change)

Mo $5 i$

M4 $5 \%$

Consumer Credit 5

Interest rates (year average)

Threc-month interbank rate 2 ,

Ten-year Government bond yield $2 /$

Balance of Payments

Trade balanee (in percent of GDP)

Current acçount (in percent of GDP)

Reserves (end of period, in billions ol SDRs) $5 / 6$ !

Fund Position ( $\Lambda$ s of December 31, 1999)

Holdings of currency (in percent of quota)

Holdings of SDRs (in percent of allocution)

Quota (in millions of SDRs)

Exchange Rate

Exchange ratc regime

Present rate (January 27, 2000)

Nominal effective rate $(1995=100) 2 /$

Real effective exchange rate $(1995=100) 5 / 7 /$

$\begin{array}{rrrrrr}2.8 & 2.6 & 3.5 & 2.2 & 1.9 & 3.0 \\ \ldots & -0.9 & 0.4 & 0.9 & 0.2 & 0.4 \\ 1.8 & 3.0 & 3.7 & 4.1 & 3.4 & 3.7 \\ 2.8 & 3.0 & 2.8 & 2.7 & 2.3 & 2.2 \\ 8.1 & 7.4 & 5.7 & 4.7 & 4.3 & 4.7 \\ 8.7 & 8.2 & 7.0 & 6.3 & 5.9 & \ldots \\ 16.4 & 16.8 & 18.0 & 18.0 & 16.6 & 16.9 \\ 17.0 & 17.0 & 17.2 & 17.9 & 17.7 & 18.2\end{array}$

$\begin{array}{rrrrrr}-5.1 & -3.8 & .0 .9 & 0.5 & 0.6 & 0.4 \\ -4.9 & -3.6 & -0.9 & 0.5 & 0.5 & 0.3 \\ 44.5 & 45.5 & 43.3 & 40.8 & 38.9 & 36.9\end{array}$

$\begin{array}{rrrrr}5.6 & 6.7 & 6.5 & 5.7 & 8.8 \\ 9.9 & 9.6 & 5.7 & 8.2 & 3.2 \\ 17.4 & 13.7 & 13.8 & 16.2 & 12.4\end{array}$

$\begin{array}{rrrrrr}6.7 & 6.0 & 6.8 & 7.3 & 5.5 & \ldots \\ 8.2 & 7.8 & 7.0 & 5.5 & 5.2 & \ldots \\ & & & & & \\ -1.6 & -1.7 & -1.5 & -2.5 & -3.0 & -3.6 \\ -0.5 & -0.1 & 0.8 & 0.0 & -1.1 & -1.2 \\ 33.1 & 32.3 & 28.0 & 27.6 & 37.0 & \ldots\end{array}$

64.2

19.5

$10,738.5$

Floating exchange rate US $\$ 1=£ 0.61$

$\begin{array}{lllll}100.0 & 101.7 & 118.5 & 122.5 & 122.3 \\ 1000 & 102.3 & 120.5 & 128.1 & 129.8\end{array}$

3.0

4

Sources: ONS; HM Treasury; Bank of England; IMF, International Financial Statistics; INS; and staff estimates.

1/ Staff projections, except where noted.

2/ For 1999, actual data.

3/ October 1999.

4/ Fiscal year beginning Aprit 1.

5/ The data for 1999 corresponds to November.

6. Including gold at national valuation.

$7 i$ Based on consumer prices. 
Table 2. United Kingdom: Contribution to Growth

(Quarterly growth rates)

\begin{tabular}{|c|c|c|c|c|c|c|c|c|}
\hline & \multirow[b]{2}{*}{ 1999Q1 } & \multirow[b]{2}{*}{$1999 Q_{2}$} & \multirow[b]{2}{*}{$1999 Q 3$} & \multicolumn{5}{|c|}{ Projections } \\
\hline & & & & $1999 Q 4$ & $2000 Q 1$ & $2000 Q_{2}$ & $2000 Q^{3}$ & $2000 Q^{4}$ \\
\hline Real GDP growth & 0.2 & 0.6 & 0.9 & 0.9 & 0.7 & 0.5 & 0.5 & 0,5 \\
\hline $\begin{array}{l}\text { Domestic demand } \\
\text { of which: }\end{array}$ & 1.3 & 0.2 & 0.8 & 1.5 & 1.1 & 0.7 & 0.7 & 0.5 \\
\hline Private consumption & 1.0 & 0.7 & 0.4 & 0.5 & 0.5 & 0.5 & 0.5 & 0.4 \\
\hline Private investment & 0.2 & 0.1 & 0.0 & 0.1 & 0.2 & 0.1 & 0.1 & 0.1 \\
\hline Public expenditure & 0.2 & 0.0 & 0.1 & 0.2 & 0.2 & 0.2 & 0.2 & 0.2 \\
\hline Stockbuilding & -0.1 & -0.8 & 0.2 & 0.6 & 0.3 & 0.0 & -0.1 & -0.1 \\
\hline $\begin{array}{l}\text { Foreign balance } \\
\text { of which: }\end{array}$ & -1.0 & 0.5 & 0.2 & -0.5 & -0.4 & -0.2 & -0.1 & 0.0 \\
\hline Imports & -0.6 & -0.2 & -1.7 & -1.0 & -0.5 & -0.4 & -0.2 & -0.2 \\
\hline Exports & -0.4 & 0.6 & 1.9 & 0.5 & 0.1 & 0.2 & 0.2 & 0.1 \\
\hline
\end{tabular}

Sources: Office for National Statistics (ONS); and staff projections. 
Table 3. United Kingdom: Medium-Term Scenario

(Percentage change, unless otherwise indicated)

\begin{tabular}{|c|c|c|c|c|c|c|c|}
\hline & 1998 & 1999 & 2000 & 2001 & 2002 & 2003 & 2004 \\
\hline Real domestic demand & 4.1 & 3.4 & 3.7 & 2.1 & 2.8 & 2.5 & 2.6 \\
\hline Private consumption & 3.4 & 4.0 & 3.2 & 2.7 & 2.4 & 2.1 & 2.2 \\
\hline Government consumption & 1.0 & 3.5 & 2.6 & 2.3 & 2.4 & 2.3 & 2.4 \\
\hline Fixed investment & 9.9 & 4.4 & 3.8 & 3.2 & 4.8 & 3.9 & 3.9 \\
\hline Residential & 6.1 & -2.6 & 2.7 & 2.3 & 4.5 & 3.5 & 3.5 \\
\hline Business & 10.9 & 6.5 & 3.1 & 2.5 & 4.5 & 3.5 & 3.5 \\
\hline Stocks 1/ & 0.0 & -0.6 & 0.5 & -0.2 & 0.0 & 0.0 & 0.0 \\
\hline External balance $1 /$ & -2.1 & -1.6 & -0.8 & -0.3 & -0.8 & -0.4 & -0.4 \\
\hline Exports & 2.0 & 3.1 & 5.2 & 2.8 & 3.6 & 5.1 & 5.4 \\
\hline Imports & 8.4 & 7.4 & 7.0 & 3.1 & 5.2 & 5.3 & 5.6 \\
\hline Current account 2 & 0.0 & -1.1 & -1.2 & -1.6 & -1.8 & -1.9 & -2.0 \\
\hline Real GDP & 2.2 & 1.9 & 3.0 & 2.0 & 2,2 & 2.2 & 2.3 \\
\hline \multicolumn{8}{|l|}{ Inflation } \\
\hline \multicolumn{7}{|l|}{ RPI (excluding mortgage } & 2.5 \\
\hline \multicolumn{8}{|l|}{ Employment and productivity } \\
\hline Employment & 1.1 & 0.4 & -0.2 & 0.0 & 0.1 & 0,2 & 0.4 \\
\hline Average unemployment rate 3 / & 4.7 & 4.4 & 4.7 & 4.8 & 5.1 & 5.2 & 5.2 \\
\hline Productivity & 1.2 & 1.5 & 3.1 & 2.0 & 2.1 & 2.0 & 1.9 \\
\hline
\end{tabular}

Sources: Office for National Statistics; and staff projections.

1/ Contribution to the growth of GDP.

2/ In percent of GDP.

$3 /$ in percent. 
Table 4. United Kingdom: Medium-Term Fiscal Balances

( In percent of GDP)

\begin{tabular}{|c|c|c|c|c|c|c|c|c|c|c|c|c|c|c|}
\hline & \multirow{2}{*}{$\begin{array}{c}\text { Prov. 2 } \\
\text { 1998/1999 }\end{array}$} & \multicolumn{3}{|c|}{$1999 / 2000$} & \multicolumn{2}{|c|}{$2000 / 2001$} & \multicolumn{2}{|c|}{$2001 / 2002$} & \multicolumn{2}{|c|}{$2002 / 2003$} & \multicolumn{2}{|c|}{$2003 / 2004$} & \multicolumn{2}{|c|}{$2004 / 2005$} \\
\hline & & Budget $\mathbf{I}^{\prime}$ & Pre-Budget $2 I$ & Pij. & Pre-Budget $2 /$ & Fij. & Prs-Budgel $1 /$ & Prij. & Pre-Budget 2 & Pтj. & Pre-Budget $2 y$ & $\mathrm{Prj}$ & Pre-Budget 2 & Prj. \\
\hline \multicolumn{15}{|l|}{ General gavernment $3 f$} \\
\hline Current balanes & 1.2 & 0.3 & 1.1 & 1.3 & 1.1 & 1.3 & 1.3 & 1.6 & 1.3 & 1.2 & 1.1 & 1.J & 1.0 & 1.0 \\
\hline Current IEvernut & 38.9 & 38.9 & 3.3 & 39.2 & 39.3 & 39.0 & 39.4 & 39.2 & 39.4 & $\$ 9.2$ & 39.3 & 391 & 39.1 & 38.9 \\
\hline Current expenditure 4 & 37.7 & 38.6 & 38.2 & 37.8 & 38.1 & 37.7 & 38.2 & 37,6 & 38.2 & 38.0 & 38.2 & 38.0 & 38.2 & 37.9 \\
\hline Capital halances & $-0,7$ & .0 .8 & 0.8 & -0.8 & .0 .9 & -0.9 & .1 .1 & -1.1 & -1.3 & -1.3 & -1.5 & -1.5 & -1.5 & .1 .5 \\
\hline Gross capital expenditure & 1.9 & 1.9 & 2.0 & 2.0 & 1.1 & 3.1 & 2.1 & 8.2 & 2.5 & 2.4 & 2.6 & 2.6 & 2.6 & 2.6 \\
\hline Operall baltance 5 & 0.5 & .0 .5 & 0.3 & 0.6 & 02 & 0.4 & 0.2 & 0.5 & -6.1 & -0.1 & -0.4 & .0 .3 & .0 .5 & -0.5 \\
\hline Werall balance (Maastricht definition) & 0.5 & -0.3 & 0.3 & 0.6 & 03 & 0.4 & 0.2 & 0.5 & -0.1 & -0.6 & -0.4 & .0 .4 & -3.5 & .0 .5 \\
\hline GToss detht & 46.7 & 45.9 & 44.9 & +4.5 & 43.1 & $\mathrm{~d} 2.3$ & 41.3 & 40.3 & 39.9 & 38.9 & 38.8 & 379 & $3 \mathbf{3}, 0$ & 37.7 \\
\hline \multicolumn{15}{|l|}{ Puhlic vecter } \\
\hline Curcent balinges & 3.1 & 0.1 & 1.0 & 1.2 & 1.0 & 1.2 & 1.2 & 1.5 & 5.2 & 1.2 & 1.1 & 1.1 & 10 & 09 \\
\hline Ciment reverne & 39.2 & 39.2 & 39.5 & 39.5 & $39.6^{\circ}$ & 39.3 & 33.7 & 39.5 & 39.8 & 39.6 & 39.7 & 39.5 & 39.5 & 39.2 \\
\hline Cunent experditure 4 & 38.1 & 39.1 & 38.6 & 38.2 & 38.6 & 38.1 & 38.5 & 38.0 & 38.6 & 38.3 & 38.5 & 383 & 38.5 & 38.3 \\
\hline Capital balance & -0.6 & -0.6 & -0.7 & 0.7 & -09 & .0 .9 & -1.1 & -11 & .1 .3 & -1.3 & -1.5 & $-1,3$ & .1 .5 & -1.9 \\
\hline Capital fcvenue and depreciation & 1.6 & 1.8 & 1.6 & 1.6 & 16 & 1.6 & 1.6 & 1.6 & 1.5 & i.5 & 1.5 & 1.5 & 1.5 & 1.5 \\
\hline Grosi capital expenditure & 2.2 & 2.4 & 2.3 & 23 & 2.5 & 2.5 & 2.6 & 2.6 & 2.9 & 2.8 & 3.0 & 30 & 2.9 & 29 \\
\hline Overall balasce $\$$ & 6.5 & -0.5 & 0.2 & 6.5 & 0.I & 0.3 & 0.1 & 0.5 & -10.1 & -41 & -0.4 & -0.4 & -0.5 & -0.5 \\
\hline Central qovernment & 0.3 & -0.5 & 0.3 & 3.6 & 0.2 & 0.4 & 0.3 & 0.7 & 0.1 & 0.1 & -0.2 & -0.2 & .0 .5 & -0.5 \\
\hline Lotel govelnulents & .. & .. & $-\cdot$ & .. & .. & -. & -1.1 & $-0]$ & -0.1 & 0.1 & -0.1 & $-0,1$ & .. & .. \\
\hline Publie corporations & $-\cdot$ & $-\cdot$ & -0.1 & -6.1 & .0 .1 & .0 .1 & -- & -. & -- & -- & -- & -- & -. & .. \\
\hline Public sector net debt & 40.8 & \$0.3 & 39.2 & 36.9 & 37.7 & 36.9 & 36.1 & 35.1 & 34.9 & 33.9 & 33.9 & 33.0 & 33.3 & 32.4 \\
\hline \multicolumn{15}{|l|}{ Menorandum: } \\
\hline Public sector struetural balance & 0.2 & -. & 0.2 & 0.3 & 0.2 & .- & 0.2 & 0.2 & -0.1 & -0.2 & -0.4 & -0.4 & -0.5 & -0.6 \\
\hline
\end{tabular}

Sources: KM Trensury; Offict for National Statistics, and staff estimales

I/Eased un the projections of the $1999 / 2000$ budget presented to Parlianent in March 1999.

2y Based or the Pre-Budget Report presented to Parlyennent in Novernher 1999.

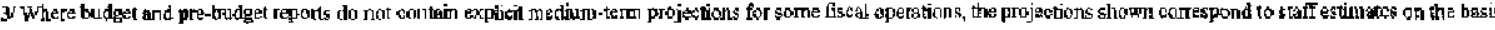

of discussions with the authnnities.

4 Thduding deprecialion.

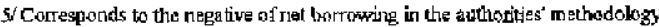


Table 5. United Kingdom: Relative Productivity Position

(1996 unless otherwise indicated; indices, UK equals 100)

\begin{tabular}{|c|c|c|c|c|}
\hline & UK & US & France & Germany \\
\hline GDP per capita & 100 & 137 & 105 & 113 \\
\hline GDP per person engaged & 100 & 129 & 126 & 126 \\
\hline GDP per hour & 100 & 121 & 132 & 129 \\
\hline Market (non-government) output per hour & 100 & 128 & 120 & 131 \\
\hline Capital per hour worked (capital intensity, 1995) & 100 & 128 & 149 & 172 \\
\hline Total factor productivity (1995) & 100 & 112 & 118 & 109 \\
\hline
\end{tabular}

Source: Mary OMahony: Britain's Productivity Performance 1950-1996: An International Perspective (National Institute of Economic and Social Research, 1999). 


\section{The Reform of the U.K. Pension System}

The future fiscal burden stemming from the existing pension system in the United Kingdom is generally considered small in relation to other comparable economies. Thus, for example, an OECD study estimated the net present value of future liabilities of the current public pension system at about 24 percent of 1994 GDP in the United Kingdom, while it was 62 percent in Germany, 70 percent in Japan, and 102 percent in France. ${ }^{1}$ Similar conclusions were reached by recent studies based on generational accounting methods ${ }^{2}$ These differences reflect two key aspects of the U.K. pension system (i) the substantial private funding of pensions; and (ii) the relatively limited provision of benefits through public pensions.

The Government considers, however, that the current pension system does not provide adequate pension coverage to about 25 percent of the labor force, while the benefits provided to those that are covered could, in time, turn out to be insufficient for low-income groups. The proposed pension reforms are intended to expand the pension benefits of the lowest paid while simultaneously bolstering the role of privately funded pensions for others. The authorities have announced their intention to increase the private-public coverage ratio of pensions to $50: 50$ by the year 2025 and $60: 40$ by the year 2050 , compared with the current ratio of 40:60. Another aim of the reforms - related to increased private funding-is to increase national savings.

\section{The current system}

The current pension system has two tiers: (i) a basic flat benefit state pension linked to inflation (with occasional higher increases) and (ii) an earnings- or contribution-related second pension. The first tier is government-provided and covers 10.6 million individuals at an annual cost of about 4.7 percent of GDP. It consists of a flat rate pension of $£ 66$ per week for a single pensioner since April 1999, or about 15 percent of average earnings. This first tier is complemented by a several means-tested benefits and income support programs, such as the minimum income guarantee (indexed to earnings since April 1999).

The second tier can be provided by the government through the State Earnings-Related Pension (SERPS), or by the private sector either through an employer-sponsored

\footnotetext{
'See Roseveare et al. "Aging Populations, Pension Systems and Government Budgets" (OECD Economics Department Working Papers No. 68, 1996).

${ }^{2}$ See Cardarelli et al. "Generational Accounting in the UK" (National Institute for Economic and Social Research, Discussion Paper No 47, 1999); "Generational Accounting in Europe," European Economy-Reports and Studies: a study coordinated by Prof. Raffelhüschen (University of Freiburg, 1999, forthcoming); and Banks et al. "What Can We Learn About Pension Reform from Generational Accounts for the UK" (Institute for Fiscal Studies, Working Paper No. W99 16, 1999).
} 
occupational pension or through a government-approved personal pension (the so-called "appropriate personal pension schemes") contracted individually with a private financial institution. The government-run pension schemes - the basic and SERPS pensions-are financed on a pay-as-you-go basis, while private schemes-either occupational or personal pensions - are capitalized (i.e., funded). The first tier basic state pension scheme covers all employees and self-employed, while participation in the second tier is only compulsory for employees earning above a threshold. The latter group must join an occupational pension, if they so choose and one is available from their employer, contract a personal pension, or otherwise enroll in SERPS. Second tier pensions are optional for the self-employed, who cannot enroll in SERPS, but can choose to join a personal pension scheme. ${ }^{3}$

The basic pension is paid from the National Insurance Fund. National Insurance (NI) contributions are compulsory for all employees with earnings above the lower earnings limit (LEL), currently $£ 66$ per week ${ }^{4}$, and the self-employed with earnings above $£ 3,770$ per year. Employees with earnings above the LEL are also required to enroll in a second tier pension scheme. NI contributions are paid on earnings between the LEL and the upper earnings limit (UEL) - currently $£ 500$ per week. Employers pay NI contributions on wage and salary payments to employees above the earnings threshold (ET)-currently $£ 83$ per week. Contribution thresholds, such as the ET, LEL and UEL are revised annually.

If employees are enrolled in a nongovernment pension scheme (occupational or personal pensions), part of their NI contributions are transferred to their pension administrator-in that case, the second tier pension is said to be "contracted out." The employee NI contribution rate is 10 percent for those enrolled in SERPS and 8.4 percent for those covered by a contracted-out employer-sponsored occupational pension scheme. A 10 percent rate is also applicable to employees covered by a private scheme not sponsored by their employer. In this case, however, an annual rebate-which increases with age up to 9 percent - is paid through the tax administration to the pertinent pension scheme. Employers that do not run occupational pension schemes pay a 12.2 percent rate on earnings above the ET.

Occupational pension schemes receive a rebate on employees' and employers' contributions based on the characteristics of the occupational pension scheme-typically between 0.6 percent and 3 percent of wages and salaries subject to contribution

\section{The envisaged reforms}

Under the proposed new system, the first-tier basic pension will remain essentially unchanged. Within the second tier, occupational and personal pensions will also remain,

\footnotetext{
${ }^{3}$ Occupational pensions are provided by employers and therefore are not typically available to self-employed persons.
} ${ }^{4}$ The LEL will be increased to 274 per week as of April 6, 2000. It will be increased further
in subsequent years to align it with the ET. 
whereas SERPS will be replaced by the State Second Pension (SSP) in April 2002 and a new type of pensions, the stakeholder pensions (SP), will be introduced.

The SSP will be financed on a pay-as-you-go basis and target those employees earning below

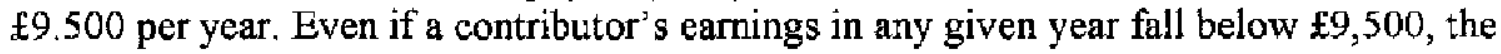
benefits will be determined as if he or she earned at least $\$ 9,500$. Thus, benefits will not be lower than those corresponding to a contributor who had earned $£ 9,500$ per year during all his or her active contributing life. While the SSP contribution will increase proportionally to earnings up to the UEL, benefits will increase at a much lower rate - in fact, the intention is to implement a transition in SSP benefits in a manner that, over time, makes them converge to a flat rate pension. In the short term and compared to the existing SERPS, the SSP could be more advantageous for those earning up to around $£ 21,600$ per year.

The new SP scheme will target those employees with earnings above $£ 9,500$ per year who switch jobs often or work for employers who do not offer occupational pensions. These pensions will be provided by the private sector on a funded basis, under strict monitoring and specific standards defined by the government (in consultation with the pension industry). The standards and modalities of the SP are still under discussion. Given the generally volatile employment histories and low income levels of the target group, the government intends to make it easy to transfer SPs between jobs. Also, in view of the potential costs of administering these pensions, the government is seeking to define administrative charges as a single uniform percentage ( 1 percent) of the value of the fund.

The proposed reform will also encompass enhanced incentives for contributors to transfer to privately-provided pensions through more generous rebates to these schemes of NI contributions. The system of rebates is currently under discussion and is considered a key element if privately-provided pensions are to offer benefits that compete favorably with the SSP (which is substantially more generous than the existing SERPS). This in turn will be critical for success in increasing the private: public pension coverage ratio.

\section{Some outstanding issues}

Although the overall architecture of the new pension system was announced early in the current legislature, some key details are not yet sufficiently defined to allow a final assessment of the long-term effects of the proposed reforms. Nonetheless, some potential concerns and risks can be identified ${ }^{5}$

- The possible increase in public pensions coverage (at least in absolute, if not in relative, terms) could imply the assumption by the government of substantially enlarged future liabilities. This is particularly so because the expanded entitlements under the SSP

\footnotetext{
${ }^{5}$ For a more detailed discussion of the pension reform, see Disney et al. Partnership in Pensions: an Assessment, The Institute for Fiscal Studies, March 1999.
} 
will be funded on a pay-as-you-go basis. Thus the risks to the fiscal accounts would need to be carefully assessed. Also, any perception of implicit public guarantees of benefits under private pension schemes, such as the SP, would need to be avoided.

- The incidence of contributions and charges associated with the SP would need to be evaluated since these could fall on employers, either because contributions are seen as a tax, rather than as a form of personal savings, or because the target group is liquidity constrained. Given the low incomes and often volatile employment histories of the target group, the administrative costs of extending private pension coverage could be sizeable (see below) and could -unless adequate safeguards are provided-increase the cost of hiring these workers.

- It is still unclear whether private pension providers will be able to offer a sufficiently attractive SP scheme to the target group. In particular, the financial industry has expressed reservations regarding the level and design of the envisaged charges under the SP and the administrative cost of providing pensions to all workers with low and irregular incomes. ${ }^{6}$ The reform of the system of NI contribution rebates to private schemes, currently under discussion, could alleviate this problem by making such rebates more generous, but only at the expense of lower budgetary revenues available to finance the public pension system. Indeed, the success of the objective of increasing the ratio of private to public pension coverage from the current ratio of 40:60 to 60:40 - and thus the future financial responsibilities of the public and private sectors---will depend critically on the relative attractiveness of the SSP versus the SP and the other alternative privately-provided pensions.

- The effects on private and aggregate savings of the reforms may be ambiguous. The intended expansion of private pension coverage through the SP may help increase private savings. On the other hand, to the extent that the expanded entitlements under the SSP will be financed on a pay-as-you-go basis, they could replace private savings and lower aggregate savings.

\footnotetext{
${ }^{6}$ The Government's proposal of a uniform management charge of 1 percent of the funds under management implies back-loaded cash flows for the insurance companies - which would prefer that the fee be defined, wholly or partly, as a percent of contributions. Also, for low income groups, the fees might not cover the administrative costs and possible future contingent liabilities (e.g., in case of eventual future litigation).
} 


\section{United Kingdom: Basic Data}

Demographic and other data:

\section{Arey}

Population (mid-1996)

Infant mortality (per 1,000 live births)

Doctors per 1,000 inhabitants

GDF per capita (1998)

\section{Composition of GDP in 1998, at current prices}

Private consumption

Public consumption

Total investment (including stockbuilding)

Total domestic demand

Exports of goods and services

Imports of goods and services

GDP at market prices (average estimate)

Selected economic data

Output and unemployment:

Real GDP (at market prices, average estimate) 1/

Manufacturing production 1 ?

Average unemployment (in perçent) 2/

Earnings and prices:

Average earnings in manafacturing $1 /$

Retail price index, excluding mortgage interest 1/

Money and interest rates:

M0 (end of period) $3 /$

M4 (end of period) 3 /

3-month Interbank rate $4 i$

10-year government bond yield 4 '

Fiscal accounts (In percent of GDP): $6 /$

General government balance

Public sector balance

Public sector net debt

Balance of payments:

Current account bslance

(In percent of GDP)

Trade balance

Fxports

Imports

Direct investment (nct)

Portfolio investment (net)

Short-term capital flows (net)

Gross reserves, official basis

(billions of SDRs, end of period)

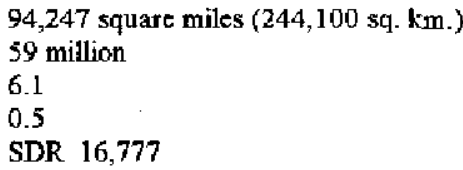

0.5

SDR 16,777

\begin{tabular}{|c|c|c|c|}
\hline $\begin{array}{c}\text { In billions } \\
\text { of Pounds } \\
545.1 \\
153.6 \\
151.3\end{array}$ & & \multicolumn{2}{|c|}{$\begin{array}{l}\text { Distribution } \\
\text { in Percent } \\
64.6\end{array}$} \\
\hline 862.2 & & \multicolumn{2}{|l|}{102.2} \\
\hline $\begin{array}{l}224.2 \\
232.7\end{array}$ & & \multicolumn{2}{|l|}{$\begin{array}{l}25.6 \\
27.5\end{array}$} \\
\hline 843.7 & & \multicolumn{2}{|l|}{100} \\
\hline 1997 & 1998 & \multicolumn{2}{|l|}{1999} \\
\hline \multicolumn{4}{|c|}{ (Annual percentage change) } \\
\hline 3.5 & 2.2 & 1.9 & $1 /$ \\
\hline 1.3 & 0.4 & 0.2 & $1 /$ \\
\hline 5.5 & 4.7 & 4.3 & $1 /$ \\
\hline 4.3 & 4.5 & 3.9 & w) \\
\hline 2.8 & 2.6 & 2.2 & 1/ \\
\hline 6.5 & 5.7 & 3.1 & $3 /$ \\
\hline 5.7 & 8.3 & 7.3 & 31 \\
\hline 6.8 & 7.3 & 5.8 & $3 /$ \\
\hline 7.1 & 5.5 & 5.6 & $3 /$ \\
\hline
\end{tabular}

(In billions of pounds sterling)

$\begin{array}{rrr}-0.9 & 0.5 & 0.6 \\ -0.9 & 0.5 & 0.6 \\ 43.3 & 40.8 & 38.8\end{array}$

\begin{tabular}{|c|c|c|}
\hline 6.6 & 0.1 & -2.8 \\
\hline 0.8 & 0.0 & -1.3 \\
\hline-11.9 & -20.8 & -5.9 \\
\hline 171.8 & 164.1 & 43.2 \\
\hline 183.7 & 184.9 & 49.1 \\
\hline-16.3 & -23.3 & -77.8 \\
\hline-24.8 & -14.2 & 76.2 \\
\hline
\end{tabular}

$28.0 \quad 27.6 \quad 37.0 \quad 3$

Source: Central Statistical Office, Economic Trends and Financial Statistics; H.M. Treasury; and staff estimates.

1/ 3rd quarter 1999.

2/ 2nd quarter 1999 .

3i November 1999. 
UNITED KINGDOM: Fund Relations

(As of December 31, 1999)

I. Membership Status: Joined 12/27/1945; Article VIII

II. General Resources Account:

SDR Million $10,738.50$

$6,891.82$

$3,846.69$

$-174.00$

Operational budget transfers (net)

III. SJPR Department:

Net cumulative allocation

Holdings

Designation Plan

IV. Outstanding Purchases and Loans:

V. Financial Arrangements:

VI. Projected Obligations to Fund:

VII. Exchange Rate Arrangement:
SDR Million

$1,913.07$

373.87

180,00

None

None

None
$\%$ Quota

100.0

64.2

35.8

$\%$ Allocation

100.0

19.5

On September 16, 1992, the U.K authorities withdrew the pound sterling from the exchange rate mechanism of the European Monetary System and have since maintained a floating regime. As of January 18,2000 the exchange rate for sterling was $\$ 1.635$

The United Kingdom continues to apply exchange restrictions vis-à-vis Iraq and Serbia and Montenegro. These restrictions have been notified to the Fund under Decision 144-(52/51): in respect of Iraq (see EBD/90/242, 7/13/90) and in respect of the Federal Republic of Yugoslavia (Serbia and Montenegro) (see EBD/92/148, 7/17/92).

\section{Article IV Consultation:}

Discussions for the 1998 Article IV consultation were conducted in London during December 11-21, 1998. The Staff Report (SM/99/36) was considered by the Executive Board on March 3, 1999 (EBM/99/21).

IX. Technical Assistance: None

X. Resident Representative: None 
Table 6. United Kingdom: Core Statistical Indicators

as of January 19, 2000

\begin{tabular}{|c|c|c|c|c|c|c|c|c|c|c|c|c|}
\hline & $\begin{array}{l}\text { Exchange } \\
\text { Rates }\end{array}$ & $\begin{array}{l}\text { International } \\
\text { Reserves }\end{array}$ & $\begin{array}{l}\text { Central } \\
\text { Bank } \\
\text { Balance } \\
\text { Sheet }\end{array}$ & $\begin{array}{c}\text { Reserve/ } \\
\text { Base } \\
\text { money }\end{array}$ & $\begin{array}{l}\text { Broad } \\
\text { Money }\end{array}$ & $\begin{array}{l}\text { Interest } \\
\text { Rates }\end{array}$ & $\begin{array}{l}\text { Consumer } \\
\text { Price } \\
\text { Index }\end{array}$ & $\begin{array}{l}\text { Exports/ } \\
\text { Imports }\end{array}$ & $\begin{array}{l}\text { Current } \\
\text { Account } \\
\text { Balance }\end{array}$ & $\begin{array}{l}\text { Overall } \\
\text { Govern- } \\
\text { ment } \\
\text { Balance }\end{array}$ & $\begin{array}{l}\text { GDP/ } \\
\text { GNP }\end{array}$ & $\begin{array}{c}\text { External } \\
\text { Debt/ } \\
\text { Debt Service }\end{array}$ \\
\hline $\begin{array}{l}\text { Date of Latest } \\
\text { Observation }\end{array}$ & $01 / 20 / 2000$ & $12 / 90$ & $12 / 99$ & $12 / 99$ & $12 / 99$ & $01 / 20 / 2000$ & $12 / 99$ & $12 / 99$ & $99 Q 3$ & $12 / 2000$ & 9903 & 1998 \\
\hline Date Received & $01 / 20 / 2000$ & December & December & December & December & $01 / 20 / 2000$ & December & December & December & Decernber & December & Sept. 99 \\
\hline $\begin{array}{l}\text { Frequency } \\
\text { of Data }\end{array}$ & Daily & Monthly & Monthly & Monthly & Monthly & Daily & Monthly & Monthly & Quarterly & Monthly & Quarterly & Aппияа \\
\hline $\begin{array}{l}\text { Frequency } \\
\text { of Reporting }\end{array}$ & Daily & Monthly & Monthly & Monthly & Motathly & Daily & Monthly & Monthly & Quarterly & Monthly & Quarterly & Annual \\
\hline Source of Updatc & TRE & ONS & $\begin{array}{l}\text { BOE } \\
\text { Press Rel. }\end{array}$ & \begin{tabular}{|l} 
BOE \\
Press Rel.
\end{tabular} & \begin{tabular}{|l} 
BOE \\
Press Rel.
\end{tabular} & \begin{tabular}{|l|} 
RES \\
Reuters \\
Bloomberg
\end{tabular} & $\begin{array}{l}\text { ONS } \\
\text { Press Rel. }\end{array}$ & $\begin{array}{l}\text { ONS } \\
\text { Press Rel. }\end{array}$ & $\begin{array}{l}\text { ONS } \\
\text { Press Rel. }\end{array}$ & $\begin{array}{l}\text { ONS } \\
\text { Press Rel. }\end{array}$ & $\begin{array}{l}\text { ONS } \\
\text { Press Rel. }\end{array}$ & ONS \\
\hline $\begin{array}{l}\text { Mode of } \\
\text { Reporting }\end{array}$ & Electronic & Electronic & $\begin{array}{l}\text { Publica / } \\
\text { Electronic }\end{array}$ & $\begin{array}{l}\text { Publica. } / \\
\text { Electronic }\end{array}$ & $\begin{array}{l}\text { Publica./ } \\
\text { Electronic }\end{array}$ & Electronic & Electronic & Electronic & Electronic & Electronic & Electronic & Electronic \\
\hline Confidentiality & Published & Published & Published & Published & Published & Published & Published & Published & Published & Published & Published & Published \\
\hline $\begin{array}{l}\text { Frequency of } \\
\text { Publication }\end{array}$ & Daily & Monthly & Monthly & Monthly & Monthly & Daily & Monthly & Monthly & Quarterly & Monthly & Quarterly & Annual \\
\hline
\end{tabular}




\section{United Kingdom - Statistical Information}

The United Kingdom maintains high standards of economic data provision. The authorities publish a full range of economic and financial data that is available electronically and have subscribed to the Special Data Dissemination Standard (SDDS). The UK shifted to ESA95 in September 1997. The main statistical change was the adoption of a wider concept of capital formation, to include computer software, mineral exploration, and military dual-use assets. It also reclassified some expenditures from net investment to depreciation. Other changes included a rebasing of the constant price estimates to a price base of 1995 , a new constant price estimate of government output, and major improvements to the business register. 


\section{INTERNATIONAL MONETARY FUND}

EXTERNAL

\section{Public Information Notice}

Public Information Notice (PIN) No. 00/17

FOR IMMEDIATE RELEASE

March 6, 2000
International Monetary Fund $70019^{\text {th }}$ Street, NW

Washington, D. C. 20431 USA

\section{IMF Concludes Article IV Consultation with the United Kingdom}

On March 1, 2000 the Executive Board concluded the 1999 Article IV consultation with the United Kingdom. ${ }^{1}$

\section{Background}

The economy has bounced back from the effects of fast year's global slowdown which led to a temporary pause in the U.K.'s output growth in late 1998 and early 1999. Exports and related movements in inventories accounted for most of the decline in growth. Domestic demand, and especially consumer spending, remained strong throughout and contributed to making the slowdown in economic activity shorter and shallower than originally expected. Growth picked up strongly in the last three quarters of 1999 to an average annualized rate of about 3 percent, reflecting both buoyant consumption expenditures and, more recently, an increase in exports. Resource utilization has remained high and the economy is now estimated to be roughly at potential output. Unemployment declined further from its peak at about 101/2 percent (on a claimant count basis) in the early 1990's to a 25-year low of 4 percent.

Inflation pressures have remained largely latent owing mainly to the lagged effect of the sterling appreciation, declines in price-cost margins due to increased competition and deregulation, and enhanced efficiency of labor markets. RPIX inflation has been below the 21/2 percent policy target. House prices and mortgage equity withdrawals, however, have picked up since the beginning of 1999. Indications of price pressures in the labor market have been

\footnotetext{
'Under Article IV of the IMF's Articles of Agreement, the IMF holds bilateral discussions with members, usually every year. A staff team visits the country, collects economic and financia information, and discusses with officials the country's economic developments and policies. On return to headquarters, the staff prepares a report, which forms the basis for discussion by the Executive Board. At the conclusion of the discussion, the Managing Director, as Chairman of the Board, summarizes the views of Executive Directors, and this summary is transmitted to the country's authorities. In this PIN, the main features of the Board's discussion are described.
} 
mixed, with eamings growth increasing to the $4 \frac{1}{2}-5$ range, outstripping productivity, while pay settlements trended down to about $3 \frac{1}{2}$ percent.

The real exchange rate appreciated sharply in 1997, reflecting both nominal appreciation and an increase in unit labor costs, and has remained strong since. The current account shifted to a deficit of $1 \% / 4$ percent of GDP in 1999 , with net exports contributing negatively to growth. However, exporters appear to be adjusting to the high level of sterling and there has been little evidence of a sustained decline in the U.K.'s share of world or European markets. The export slowdown in late 1998 appears to have been driven mainly by the decline in demand in Europe and Asia, with the subsequent export rebound being associated with recovery in these markets.

The Bank of England's Monetary Policy Committee (MPC) continued lowering the policy rate during the first three quarters of 1999 to address the ongoing decline in activity. However, it reversed policy direction in September -as the recovery firmed and medium-term risks of higher-than-targeted inflation began to emerge-and, by February 2000, had increased the rate by a total of 100 basis points to 6 percent. The budgetary outturn in fiscal year 1998/1999 and the current year $1999 / 2000$ have been stronger than originally envisaged. The November Pre-Budget Report revised the projected fiscal path upward to reflect the ongoing overperformance which has been prompted by the stronger-than-expected economic recovery and some structural fiscal improvements. Both the monetary and fiscal policy frameworkswith their medium-term orientation and emphasis on transparency and accountability-have delivered a high degree of policy credibility and private sector confidence.

Given the improved macroeconomic performance and high levels of resource utilization, policies have increasingly focused on achieving long-term goals: a more equitable sharing of economic gains_-particularly through the alleviation of poverty and inroads into long-term unemployment; pension reform; closing the sizeable productivity gap between the United Kingdom and other major industrial countries; and strengthening the structural underpinnings of the economy, in part with a view to clarifying the implications of any eventual decision whether to join EMU.

In this regard, the Government's recent efforts in the welfare and labor market area (particularly the New Deal, the Working Families Tax Credit and the National Minimum Wage) are focused on enhancing work incentives and alleviating poverty. The recent proposals on pension reform are aimed at increasing the public pension benefits of the lowest paid and boistering the role of privately funded pensions for others. On the productivity gap, shortfalls in the U.K.'s labor productivity seem to reflect, among other factors, sizable gaps in its human and physical capital stock. The authorities' strategy to boost productivity thus features both increasing public sector physical and human capital investment and improving the climate for private investment, in part through efforts to increase competition, improve deregulation, and encourage enterprise and innovation. Since an efficient and stable capital market is also an essential element in this regard, Bank of England has been given responsibility for the overall stability of the financial system and the Financial Services Authority has been charged with ensuring the effective and efficient regulation of the increasingly integrated financial services industry. 


\section{Executive Board Assessment}

Directors commended the authorities for the United Kingdom's impressive economic performance over much of the 1990s, during which growth has been strong and sustained, and both unemployment and inflation have declined to enviable levels. Recently, the economy had weathered the slowing of global demand in late 1998, and growth was resuming based on buoyant domestic demand, and more recently a pickup in exports. While the strength of sterling was a source of uncertainty, Directors believed that the authorities' strong policy frameworks and their track record of skillful policy management would be conducive to a continuation of sustained growth and low inflation. At the same time, a number of Directors expressed concem at the real appreciation of the exchange rate, noting that the effects of exchange rate changes on trade are typically lagged, and suggested that the authorities will need to remain alert to the implications of sterling's strength for competitiveness.

Looking ahead, Directors considered that short-term risks were mostly on the upside, with the main challenge being to prevent overheating. The immediate prospects for inflation remained benign owing to favorable, but most likely temporary, factors. However, most Directors thought that resource pressures were likely to increase over time, given that above potential growth had resumed with the economy at or close to full employment. Some Directors noted the additional inflation risks stemming from a potential depreciation of sterling as the euro strengthened. On the other hand, several Directors underscored the possibility of more favorable inflation outcomes stemming from favorable structural shifts in the economy.

Absent external deflationary shocks, most Directors agreed that policies-in the first instance monetary policy - would likely need to tighten further over the course of this year. In this regard, they took note of the Bank of England's record in taking prompt, forward-looking action, including the rate increases that had already taken place.

Given cyclical considerations and the strong real exchange rate, Directors underscored the need to ensure that the fiscal stance remains supportive of monetary policy. While welcoming the stronger than anticipated budgetary outturn likely for fiscal year 1999/2000, which impties attainment of an overall surplus on a Maastricht basis, they urged that the March 2000 budget preserve the margins built up by the overperformance during the previous year. Some Directors went further to suggest that a strengthening of the real exchange rate would warrant a discretionary tightening of fiscal policy.

Many Directors also stressed the importance of consolidating the credibility of the government's newly established fiscal framework by abiding by the oxisting three-year budget plans.

Directors considered that the remarkable performance of the U.K. economy in recent years owes much to the strengthening of policy frameworks. These frameworks had helped foster sound macroeconomic and structural policies and-through their emphasis on transparency and accountability-hatd given a high degree of credibility to policies and had bolstered private 
sector confidence. Many Directors also pointed to the key role that earlier structural reforms, particularly in labor markets, had played in allowing the supply side to respond flexibly.

Directors praised the effectiveness of the inflation targeting framework in the United Kingdom, commending in particular the forward-looking, transparent, and preemptive aspects of the approach. They considered it emblematic of the success of the framework that the United Kingdom had the lowest inflation rate in the European Union at the end of last year, and some of the lowest long-term bond yields in the world in early 2000 . Directors noted in this regard the potential tension between the need to be both forward-looking, including about possible future policy actions, given present prospects, and the need to be transparent. In considering the staff argument that the Monetary Policy Committee's modeling framework should include a policy reaction function rather than assume a constant interest rate, all Directors agreed that policies need to be considered dynamically, and that in fact policies are formulated in a forward-looking manner in the United Kingdom. Moreover, most Directors believed that, as the transparency of the U.K. monetary policy framework is already among the highest internationally, attempts to incorporate a forward-looking view of interest rates into the published forecast could risk misleading markets and the public. Several Directors noted that these concerns should not be interpreted as precluding further progress in improving the forecasting framework by endogenizing future policy responses.

Directors considered that the fiscal framework provided a significant measure of assurance both that needed infrastructural investments would be carried out and that the public finances would be managed prudently on a sustained basis. Some Directors felt that, while the golden and debt sustainability rules provided useful guides to fiscal policy, these rules did not adequately constrain policy at present and left scope for sizable spending initiatives. They noted that there was room for adopting tighter rules, for instance, to require overall balance over the cycle. Some other Directors, however, considered that tighter fiscal rules, while perhaps helpfuf in the medium term should current measures prove inadequate, are unnecessary given the current cautious stance of fiscal policy. While welcoming the efficiency gains and improved public resource allocation arising from the strengthened fiscal framework, Directors cautioned against increased resort to indirect means of funding new initiatives such as tax expenditures. Some Directors also noted that, while fiscal transparency was high by international standards, it could be further strengthened by improvements in the area of budget reporting.

Directors praised the authorities for focusing long-term policies toward achieving greater equity and strengthening productivity. They commended the government's recent welfare and labor market reforms that were aimed at strengthening incentives to work, particularly arnong jobless households. A few Directors expressed concern about the recently announced increase in the national minimum wage, noting that it had been introduced in exceptionally propitious economic circumstances, and that adverse effects on unemployment might become evident only during an economic downtum. Directors welcomed the intention underlying the proposed pension reforms to increase the savings and coverage of those who at present are not adequately covered. They cautioned against any risk that the reforms could substantially enlarge future fiscal liabilities or increase the costs of employing low-income workers. 
Many Directors agreed that closing the productivity gap vis-à-vis other major industrialized countries was an important long-term challenge for the United Kingdom, which would require increased private and public investment on a sustained basis. Given the already strong real exchange rate and the risks of relying excessively on foreign savings, they considered that the most effective means to achieve this expansion in investment would be to increase public saving.

Directors commended the authorities' initiatives to increase competition, encourage innovation, and put in place appropriate regulatory regimes. They noted that the new financial structure seemed to be performing satisfactorily, with the key role of the Financial Services Authority (FSA) being that of regulating the increasingly integrated and complex financial services industry, and the role of the Bank of England being that of ensuring the overall stability of the financial system. It was suggested that a further examination of the experience of the FSA would be useful, especially for countries considering institutional reform of their own financial supervisory functions.

Directors agreed that entry into EMU remains a key medium-term decision for the United Kingdom. They considered that, while many considerations would influence the decision whether to join, an overriding economic case for or against entry could not be made at the present time. However, many of the factors affecting this decision, such as differences between the United Kingdom's and the euro area's relative cyclical positions, and concems over wage flexibility in the United Kingdom, were likely to change over time. The Fund must continue to focus on this critical policy issue in its ongoing surveillance activities.

Directors praised the authorities' initiatives to relieve the debt burden of the poorest countries and their commitment to increase overseas aid spending, and in this connection, they welcomed the recent increases in such assistance. They encouraged the authorities to accelerate progress toward the UN target for overseas aid spending of 0.7 percent of GNP from the 1999 level of 0.27 percent of GNP.

The United Kingdom publishes data on a sufficiently timely and comprehensive basis to permit effective surveillance.

Public Information Notices (PINs) are issued, (i) at the request of a member country, following the conctusion of the Article IV consultation for countries seeking to make known the views of the IMF to the public. This action is intended to strengthen IMF surveillance over the economic policies of member countries by increasing the transparency of the IMF's assessment of these policies; and (ii) following policy discussions in the Executive Board at the decision of the Board. As part of a pilot project, the staff report (use the free Adobe Acrobat Reader to view this pdf file) for the 1999 Article IV consultation with the United Kingdom is also available on the IMF's website (http://www.imf.org). 
United Kingdom: Selected Economic Indicators and Staff Projections

\begin{tabular}{|c|c|c|c|c|c|c|c|}
\hline & 1995 & 1996 & 1997 & 1998 & $19991 /$ & 2000 & $\boldsymbol{H}$ \\
\hline \multicolumn{8}{|l|}{ Real Economy (change in percent) } \\
\hline Real GDP & 2.8 & 2.6 & 3.5 & 2.2 & 1.9 & & 3.0 \\
\hline Output gap & $\ldots$ & -0.9 & 0.4 & 0.9 & 0.2 & & 0.4 \\
\hline Domestic demand & 1.8 & 3.0 & 3.7 & 4.1 & 3.4 & & 3.7 \\
\hline Retail price index (excluding mortgage interest) 2 & 2.8 & 3.0 & 2.8 & 2.7 & 2.3 & & 2.2 \\
\hline Unemployment rate (claimant count, in percent) $2 /$ & 8.1 & 7.4 & 5.7 & 4.7 & 4.3 & & 4.7 \\
\hline Unemployment rate (labor force survey, in percent) $3 /$ & 8.7 & 8.2 & 7.0 & 6.3 & 5.9 & $\ldots$ & \\
\hline Gross national saving (percent of GDP) & 16.4 & 16.8 & 18.0 & 18,0 & 16.6 & & 16.9 \\
\hline Gross domestic investment (percent of GDP) & 17.0 & 17.0 & 17.2 & 17.9 & 17.7 & & 18.2 \\
\hline \multicolumn{8}{|l|}{ Public Finance (in percent of GDP) 41} \\
\hline General govemment balance & -5.1 & -3.8 & -0.9 & 0.5 & 0.6 & & 0.4 \\
\hline Public sector balance & $-4,9$ & -3.6 & -0.9 & 0.5 & 0.5 & & 0.3 \\
\hline Public sector net debt & 44.5 & 45.5 & 43.3 & 40.8 & 38.9 & & 36.9 \\
\hline \multicolumn{8}{|l|}{ Money and Credit (end-year, percent change) } \\
\hline MO 5 & 5,6 & 6.7 & 6.5 & 5.7 & 8.8 & $\ldots$ & \\
\hline M4 5/ & 9.9 & 9.6 & 5.7 & 8.2 & 3.2 & $\ldots$ & \\
\hline Consumer Credit 5! & 17.4 & 13.7 & 13.8 & 16.2 & 12.4 & $\ldots$ & \\
\hline \multicolumn{8}{|l|}{ Interest rates (year average) } \\
\hline Three-month interbank rate $2 /$ & 6.7 & 6.0 & 6.8 & 7.3 & 5.5 & $\ldots$ & \\
\hline Ten-year Government bond yield $2 y$ & 8.2 & 7.8 & 7.0 & 5.5 & 5.2 & $\ldots$ & \\
\hline \multicolumn{8}{|l|}{ Balance of Payments } \\
\hline Trade balance (in percent of GDP) & -1.6 & -1.7 & -1.5 & -2.5 & -3.0 & & -3.6 \\
\hline Current account (in percent of GDP) & -0.5 & -0.1 & 0.8 & 0.0 & -1.1 & & -1.2 \\
\hline Reserves (end of period, in billions of SDRs) $5 / 6 /$ & 33.1 & 32.3 & 28.0 & 27.6 & 37.0 & $\cdots$ & \\
\hline \multicolumn{8}{|l|}{ Fund Position (As of January 31,1999 ) } \\
\hline Holdings of currency (in percent of quota) & \multicolumn{7}{|c|}{64.2} \\
\hline Holdings of SDRs (in percent of allocation) & \multicolumn{7}{|c|}{18.4} \\
\hline Quota (in millions of SDRs) & \multicolumn{7}{|c|}{$10,738.5$} \\
\hline \multicolumn{8}{|l|}{ Exchange Rate } \\
\hline Exchange rate regime & & \multicolumn{6}{|c|}{ Floating exchange rate } \\
\hline Present rate (January 27,2000 ) & & \multicolumn{6}{|c|}{ US $\$ 1=$ \&O.61 } \\
\hline Nominal effective rate $(1995=100) 2 /$ & 100.0 & 101.7 & 118.5 & 122.5 & 122.3 & $\cdots$ & \\
\hline Real effective exchange rate $(1995=100) 5 / 7 /$ & 100.0 & 102.3 & 120.5 & 128.1 & 129.8 & $\ldots$ & \\
\hline
\end{tabular}

Sources: ONS; HM Treasury; Bank of England; IMF, International Financial Statistics; INS; and IMF staff estimates.

$1 /$ Staff projections, except where noted.

2) For 1999, actual data.

3/ October 1999.

4) Fiscal year beglnning April 1.

5) The data for 1999 corresponds to November.

6/ Including gold at national valuation.

$7 /$ Based on consumer prices. 


\section{Statement by Stephen Pickford, Executive Director \\ for the United Kingdom \\ March 1, 2000}

1. Let me begin by expressing my authorities' appreciation for the efforts of Michael Deppler and his team. They have produced a useful report on the Article IV consultation, and an interesting set of background papers which address a number of topical issues.

\section{Recent economic developments and prospects}

2. A year ago some observers were anticipating a recession in the UK. Both the staff and my authorities were confident that the necessary slowdown would be shorter and shallower than had typically been the case in the past. This confidence has proved well founded. While the economy did slow significantly towards the end of 1998, growth accelerated through 1999 with output in the fourth quarter almost 3 per cent higher than a year earlier.

3. The balance of growth has also improved. Manufacturing output has picked up on the back of a very strong rise in productivity, together with increases in both overseas and domestic demand.

4. Looking forward, there continues to be little difference between the staff and $\mathrm{my}$ authorities on the prospects for the UK economy. The latest official forecast, prepared last November, was for growth this year of $2 \frac{1 / 2}{3}-3$ per cent. The staff forecast of 3 per cent is at the top end of that range. Updated official forecasts will be presented in the Budget on 21 March.

5. In recent months the outlook for the world economy has improved, and strong growth has been recorded in household wealth, income and borrowing. In response to these developments, the Bank of England's Monetary Policy Committee has concluded that the pace of growth in domestic demand needs to be restrained to achieve the government's inflation target in the medium term. The MPC has therefore acted pre-emptively in raising interest rates to $6 \%$ - a total of 100 basis points since September last year.

6. Monetary policy has the main task of managing short term macroeconomic movements, while fiscal policy is geared to ensuring sound public finances over the medium term. Nonetheless, to promote stability the government believes that fiscal policy should, where prudent and sensible, support monetary policy through the cycle, while continuing to meet the fiscal rules.

\section{Macroeconomic policy framework}

7. The government's macroeconomic policy framework seeks to entrench economic stability by establishing:

- clear long-term policy objectives for inflation and fiscal policy; 
- transparent procedural rules for monetary and fiscal policy making; and

- openness and accountability in policy making. Last year's Report on Observance of Standards and Codes (ROSC) showed that the UK exceeds many requirements of the fiscal transparency code and is highly transparent as measured against the code on monetary and financial policies. The UK is also fully compliant with the Special Data Dissemination Standards (SDDS).

\section{Fiscal policy}

8. The UK now has in place a much improved and transparent fiscal framework and two tough fiscal rules - the golden rule and the sustainable investment rule. The fiscal decisions taken in the last two and a half years have restored sound public finances.

9. However, the need to continue to meet the fiscal rules means there is no room for complacency: forecast errors on the public finances are large, and a cyclical improvement must not be confused with a structural improvement. That is why the government will maintain a cautious approach.

10. The fiscal rules are further supported by a spending framework which seeks to ensure that all spending, both capital and current, gives value for money. An important element of the new framework is that a distinction is made between current and capital spending at the departmental level, consistent with the distinction in the fiscal rules. This is designed to help remove the bias against investment inherent under the previous regime.

11. The government is also committed to raising the level of public investment in the UK within prudent limits set by the sustainable investment nule. While the fiscal rules are set to ensure sound public finances, the government has other mechanisms in place to identify worthwhile public investment. As part of the new framework, all government departments are required to produce investment strategies setting out how they manage and appraise their existing capital stock and investment programs, and how these programs contribute in a cost effective way to departments' aims and outputs. These investment strategies will be a key input to the forthcoming spending review which will determine the government's spending priorities for the next three year period.

12. The staff have also provided some suggestions in the area of budget reporting, going beyond the suggestions in last year's ROSC. This is an issue which my authorities take seriously. A number of steps have been taken since the last Article IV consultations to improve reporting, including improvements to the public finance statistical releases; and last November they published a guide to analysing UK fiscal policy, which will help to enhance public understanding of the objectives and operation of fiscal policy. Resource accounting will be introduced later this year which will bring public accounting practices more closely into line with those of the private sector. Under the Code for Fiscal Stability, the government is committed to improving Parliament's and the public's ability to scrutinise fiscal and debt management policy, and will continue to review progress in this area and to consider ways of achieving even greater transparency. The government will consider carefully the staff's additional suggestions. 


\section{Monetary policy}

13. The monetary policy framework is also highly transparent. Publication of the quarterly Inflation Report and the minutes of the monthly MPC meetings ensures that the public is well informed about monetary policy. Members of the MPC are held individually accountable for their performance.

14. To date, the framework has worked well:

- Inflation has remained stable and close to target, and monetary policy has helped the economy adjust smoothly to shocks.

- The MPC has established a track record of operating in a pro-active, forward looking manner.

- The framework has also established considerable credibility. Survey and financial market data suggest that people expect price stability to be maintained in the long term. Long term inflation expectations have fallen to around 2.3 per cent. Short term official interest rates peaked at 7.5 per cent in June 1998 , half their early 1990 s levels. And, as the staff have noted, the inflation premium in long term UK interest rates has declined to levels comparable to those of the euro area.

15. Staff agree that this framework has worked well. There is, however, one specific issue on which the views of my authorities and of the staff diverge. Staff have criticized the constant interest rate assumption underlying the inflation forecast. But it is important to be clear about how the forecast is used in the setting of interest rates. Staff's analysis of the consequences of behaving according to a mechanical policy rule based on constant interest rates is correct. But the MPC follows no such mechanical policy rule.

16. The Inflation Report presents forecasts conditioned on two possible assumptions about paths for future interest rates - a constant interest rate and the market rate. They are "what if" statements which provide an important input into the MPC's discussions and judgement about the appropriate level of rates. But neither the constant interest rate conditioning assumption, nor the market rate assumption, corresponds to any optimal profile of interest rates, nor is it a policy rule. More generally, no policy reaction function could fully encapsulate all the possible sets of circumstances that the MPC could face in setting policy. Nevertheless, my authorities appreciate the continuing dialogue with staff about the technicalities of monetary policy.

\section{Longer term structural issues and policies}

\section{Welfare to work}

17. The principles of the Welfare to Work program are now well established, although some key measures such as the Working Families Tax Credit and various elements of the New Deal have only been in effect for a few months. 
18. A thorough assessment of the specific policies would be premature at this stage. However, where preliminary assessment has been possible, it has been very positive. It shows that the National Minimum Wage - the adult rate will be raised to $£ 3.70$ in October and youth rate to $\mathbf{E 3 . 2 0}$ in June - has had no adverse effects on employment or inflation. And an assessment by the National Institute for Economic and Social Research of the early stages of the New Deal for Young People estimated that by the end of its first four years the program will have moved around one quarter of a million young people into work.

\section{Competitiveness and productivity}

19. The productivity gap between the UK and its major competitors is substantial and longstanding. My authorities are therefore committed to improving productivity performance.

20. The government's strategy for meeting this challenge is focussed on five key areas:

- $\quad$ raising investment;

- encouraging enterprise and innovation;

- $\quad$ improving skills;

- $\quad$ promoting competition and better regulation; and

- $\quad$ raising public sector productivity.

21. The new macroeconomic framework will encourage stability and investment. Also the government has: cut corporation tax; provided $£ 19$ billion of additional funds for education and skills; and $£ 1.4$ billion for science; introduced a new Competition Act; established new Public Service Agreement targets; and is seeking a doubling of public investment.

\section{Pensions}

22. The UK, like many other countries, must face the challenges presented by an ageing population. Demographic changes in the UK will be less marked than in some other countries. Nevertheless, the current system of pension provision is unlikely to meet the needs of a more flexible labour market.

23. The government's reform proposals therefore aim to gradually shift pension provision away from the government towards the private sector by encouraging a significant increase in the level of voluntary savings, through Stakeholder pensions which are more flexible and more portable than existing pensions. The reforms will build on the existing partnership between the state, employers, and private pension providers, and ensure better pensions for those on low incomes. 


\section{Financial sector}

24. In January the Financial Services Authority published the main lines of the regulatory approach it proposes to follow when it becomes the single regulator for the UK's financial services industry later this year. This approach recognises the realistic aims and limits of regulation, and the responsibilities of consumers and financial sector management. It will involve a new FSA-wide operating framework for identifying and assessing risks, including the key themes for priority action. The new operating framework will come fully into effect in 2001/02.

\section{EMU}

25. I am grateful to the staff for their analysis of the pros and cons of possible UK entry into EMU. It represents a well balanced assessment and is underpinned by a comprehensive survey of the recent academic literature on optimal currency areas and business cycle synchronicity.

26. Given the UK's opt-out status, the determining factor underpinning any government decision on EMU entry will be whether the economic benefits for the UK of joining are clear and unambiguous, based on five economic tests. The government has said that it is not realistic to expect a decision to join during this parliament, since a period of stability and settled convergence will be necessary before membership can be considered. Nevertheless, preparations are being made so that, should the economic tests be met, a decision to join a successful single currency could be made early in the next parliament. The staff's main conclusion - that "an overriding economic case for or against entry cannot be made at this moment" - is therefore consistent with the view of my authorities.

\section{Concluding remarks}

27. As always, these have been useful consultations. The fact that we will be publishing the staff report made no difference to their conduct. Staff have challenged our thinking in some areas, and we welcome this since it helps us to improve the ways in which we both formulate and present policy. 